Portland State University

PDXScholar

\title{
A Comparison of Two Methods for Measuring the Attenuation Provided by Insert-Type Hearing Protection Devices
}

Brenda Barrett Kabat

Portland State University

Follow this and additional works at: https://pdxscholar.library.pdx.edu/open_access_etds

Part of the Speech and Hearing Science Commons

Let us know how access to this document benefits you.

\section{Recommended Citation}

Kabat, Brenda Barrett, "A Comparison of Two Methods for Measuring the Attenuation Provided by InsertType Hearing Protection Devices" (1990). Dissertations and Theses. Paper 4067.

https://doi.org/10.15760/etd.5950

This Thesis is brought to you for free and open access. It has been accepted for inclusion in Dissertations and Theses by an authorized administrator of PDXScholar. Please contact us if we can make this document more accessible: pdxscholar@pdx.edu. 
AN ABSTRACT OF THE THESIS OF Brenda Barrett Kabat for the Master of Science in Speech Communication presented February 23, 1990.

Title: A Comparison of Two Methods for Measuring the Attenuation Provided by Insert-Type Hearing Protection Devices.

APPROVED BY THE MEMBERS OF THE THESIS COMMITTEE:

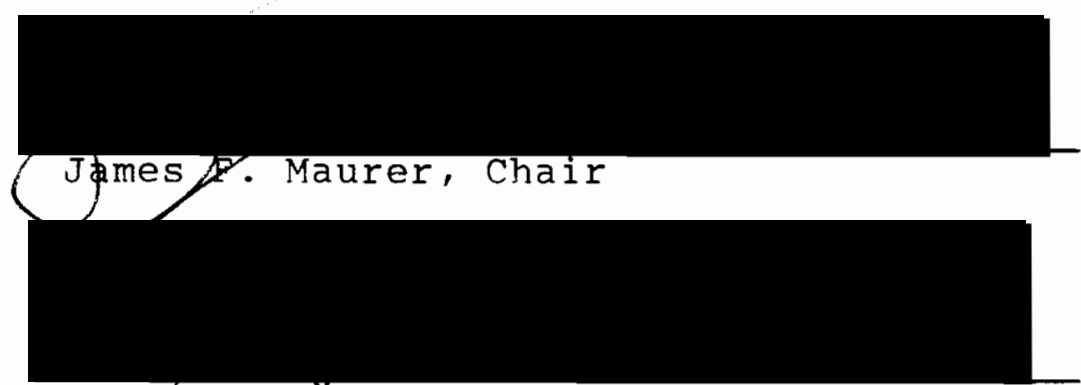

Thomás Dolán

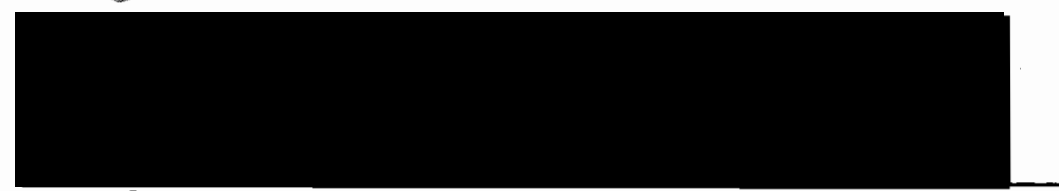

Cord Sengstake

The need for hearing protection in industry has evolved from the growing awareness of the detrimental effects of noise on hearing and recent legislation enacted to protect the hearing of noise-exposed employess through the use of hearing conservation programs. In lieu of expensive or impractical engineering and administrative controls, personal hearing protection devices (HPDs) are considered to be the 
most practical and effective means of protecting employees from the damaging effects of noise in industry today.

In order to assure that the best possible attenuation (noise reduction) is obtained with HPDs provided, some form of measurement procedure for the measurement of the attenuation provided by the HPDs needed to be developed. This resulted in the development of the ANSI Real Ear Attenuation of Ear Protectors at Threshold $(724.22,1957$, revised in 1974 and 1984). The final revision ANSI S12.6-1984 is the method currently used in the laboratory for the measurement of HPDs. This method requires the use of one-third octavebands of noise stimuli in sound field ancis impractical for use in field measurements, where measurements of "real world" attenuation are needed to determine the amount of actual protection provided to workers on the job. Laboratory studies using the ANSI methoo produce results that tend to be much higher than those obtained in field studies. This prompted the need for a method that can be tested in the field that is a valio and reliable alternative to the ANSI method. The purpose of this study was to validate the effectiveness of an alternative method of measuring HPD attenuation. The method makes use of standard portable audiometers and TDH-39 headphones with an experimental headphone/support device made of easily obtained materials. This method was found by Gaier in 1987 to be an effective method for measuring the attenuation of the E-A-R insert-type earplug. 
The present study compared the experimental method. employing pure tone stimuli, to the ANSI method, which uses one-third octave-bands of noise in sound field. Four earplugs commonly used in industry were tested for goodness of fit on ten subjects with normal hearing thresholds. Significant differences were not found between the ANSI and the experimental method at any of the frequencies tested. Significant differences $(p<.001)$ were found between frequencies, depending upon the plug type. Significant differences $(p<.01)$ were found across trials for the headphone/support method at all frequencies except $1000 \mathrm{~Hz}$.

These results indicate that this method is a valid alternative to the ANSI methoo for further research in the field, but is most reliable at one test frequency, $1000 \mathrm{~Hz}$. A field study of the headphone/support method for the determination of "real world" attenuation provided by insert-type hearing protection devices is indicated to determine if the laboratory results found in this study, or those of the Gaier study, carry over into field use. 
A COMPARISON OF TWO METHODS FOR MEASURING THE

$$
\begin{gathered}
\text { ATTENUATION PROVIDED BY INSERT-TYPE } \\
\text { HEARING PROTECTION DEVICES }
\end{gathered}
$$

by

BRENDA BARRETT KABAT

A thesis submitted in partial fulfillment of the requirements for the degree of

\author{
MASTER OF SCIENCE \\ in \\ SPEECH COMMUNICATION : \\ with an emphasis in \\ AUDIOLOGY
}

Portland State University 
TO THE OFFICE OF GRADUATE STUDIES:

The members of the committee approve the thesis of Brenda Barrett Kabat presented February 23, 1990 .

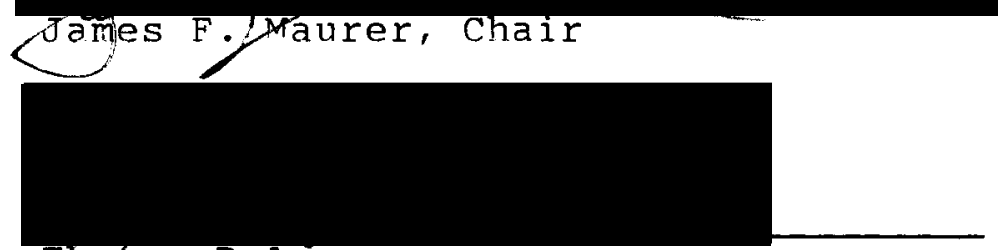

Thgrias Dolan

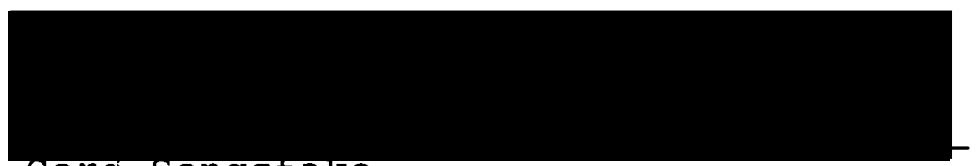

cora sengstake

APPROVED :

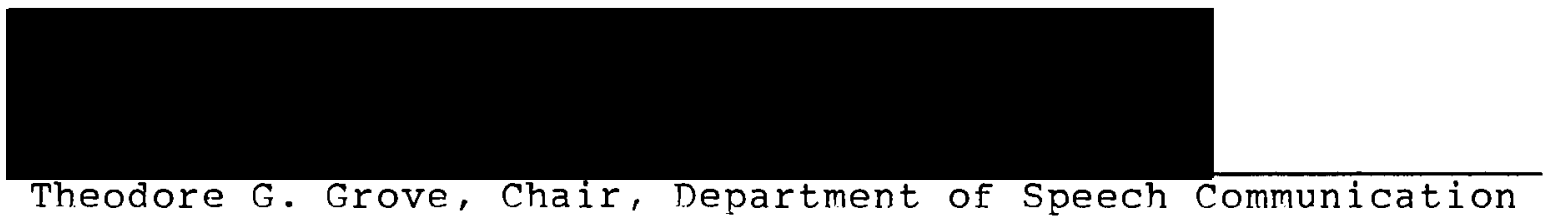

c. William Savery, Interim vice etovost for Graduate studies and Research 


\section{ACKNOWLEDGMENTS}

I would like to thank Dr. James F. Maurer for giving me the idea for this thesis and providing help and support to make the completion of this project possible; Dr. Thomas Dolan for his help, support, and guidance throughout the process of putting this together; and Brent McMullin, for his support and input at the times when I needed it most.

Special thanks go to Hocks Laboratories and Sanderson Safety Supply, both of Portland, oR, for providing the earplugs evaluated.

Innumerable thanks and appreciation go to Dr. Theodore Grove for his help in completing and analyzing the statistics required. Without his time and expertise the paper would not have been completed.

Most of my thanks, however, go to my husband, Brent L. Kabat, who supported me, 1 istened to me, and put up with me throughout the whole process and is still here to talk about it. 
TABLE OF CONTENTS

PAGE

ACKNOWLEDGMENTS

LIST OF TABLES

vi

LIST OF FIGURES . . . . . . . . . . . . . . . . . . . vii vi

CHAPTER

I INTRODUCTION

il ReView OF THE Literature . . . . . . . . . 6

History of Standards Development . . . . 6

Current ANSI Standards. . . . . . . . 7

Environment

Stimulus

The Need for An Alternative

Procedure

Alternative Methods . . . . . . . .

Standard Headphones Alone

Circumaural Headphones

Standard Headphone with Support

II METHODS . . . . . . . . . . . . . . 16

Subjects . . . . . . . . . . . 16

Instrumentation . . . . . . . . . 16

Procedure . . . . . . . . . . . 19

IV RESULTS AND DISCUSSION . . . . . . . . . 21

Results . . . . . . . . . . . . . 21

Discussion . . . . . . . . . . . . 34

V SUMMARY . . . . . . . . . . . . . . 38 
PAGE

REFERENCES

APPENDIX

A INSTRUCTIONS FOR EARPLUG INSERTION FOR THE CUSTOM-MOLDED, MAX, AND V-51R

EARPL

B RAW DATA . . . . . . . . . . . . . . . 47

C AVERAGE ATtenUATion PER PLUG-CUSTOM-MOLdEd, MAX, V-51R, AND MOLDED WITH VENT . . . . . 58

D PEARSON CORRELATION COEFFICIENTS . . . . . . 63 


\section{LIST OF TABLES}

TABLE

PAGE

I Maximum Permissible Ambient Noise Levels for Audiometric Testing . . . . . . . . .

I Manufacturer and Field Attenuation Data for the E-A-R Plug . . . . . . . . . . .

III A Comparison of Trial Means and Standard

Deviations Across Frequencies for Each

Earplug Evaluated with the Sound Field Method . . . . . . . . . . . . . .

IV A Comparison of Trial Means and Standard

Deviations Across Frequencies for Each

Earplug Evaluated with the Headphone/

Support Method . . . . . . . . . . . .

$\mathrm{V}$ Average Test-Retest Reliability of the sound

Field Method and the Headphone/support

Method by Frequency and Plug Type as

Derived from the Pearson Correlation

Coefficients . . . . . . . . . . . . . . . 


\section{LIST OF FIGURES}

FIGURE

PAGE

1. Headphone/Support Device A, Used by Gaier;

Headphone/Support Device B, Modified

Version Used in Current Study . . . . . . .

2. Earplugs Used in Current Study: 1--Solid

Custom-Molded, 2--MAX, 3--V-51R, 4--Vented

Custom-Molded . . . . . . . . . . . . .

3. A Graphic Representation of Table III Showing

the Mean Attenuation Across Trials for the

Four Earplugs Tested with the sound

Field Method . . . . . . . . . . . . .

4. A Graphic Representation of Table IV Showing

the Mean Attenuation Across Trials for the

Four Earplugs Tested with the Headphone/

Support Method . . . . . . . . . . . 25

5. A Comparison of the Attenuation obtained with

the Solid Custom-Molded Earplug for the

Sound Field Method vs. the Headphone/

Support Method . . . . . . . . . . . .

6. A Comparison of the Attenuation obtained with the MAX Earplug for the Sound Field Method

vs. the Headphone/Support Method 
7. A Comparison of the Attenuation Obtained with the V-51R Earplug for the Sound Field Method vs. the Headphone/Support Method . .

8. A Comparison of the Attenuation obtained with the Vented Custom-Molded Earplug for the Sound Field Method vs. the Headphone/ Support Method . . . . . . . . . . . .

9. A Graphic Representation of the Difference in Attenuation Obtained Across Trials for the Sound Field Method (1) and the Headphone/ Support Method (2) . . . . . . . . . 
CHAPTER I

INTRODUCTION

In order to implement an effective Hearing Conservation Program, employers must provide their noise-exposed employees with hearing protection devices (HPDS) (Williams-Steiger Occupational Safety and Health Act of 1970). Implicit in this federal requirement is the mandate that employers should also provide a means for evaluating the attenuation characteristics or noise reduction of the hearing protection devices that they provide (Berger, 1984). This need arises from observed differences between laboratory standards for attenuation and less rigorous real. world attenuation values for earplugs worn in the field (Berger, 1984).

Most employers rely on attenuation data provided by manufacturers to determine the amount of attenuation a HPD will provide. These attenuation values are based on data obtained by the manufacturer using the American National Standards Institute (ANSI S12.6-1984) laboratory procedures, which rely on specialized equipment, environments, trained subjects, and carefully fitted HPDs. Several investigators have reported that in field testing, regardless of the procedure used, lower (poorer) attenuation values are obtained than in laboratory testing (Regan, 1975, 1977; Edwards, Hauser, Moiseev, Broderson, and Green, 1978; Abe1, 
Alberti, and Riko, 1982; Gaier, 1988). In other words, 1aboratory measurements of HPDs tend to overestimate the "real world" effectiveness of the HPDs measured.

Currently, there is no single method which has proven to be economical, practical, and effective for determining the goodness of fit of HPDs in the field (Berger, 1988). Some researchers have attempted to use the standard ANSI procedure to study attenuation of HPDs at actual work sites (Regan, 1975, 1977; Eơwards et a1., 1978; Abel et a1., 1982). These studies obtained results that were comparable to those in the laboratory, but still required the use of special equipment and environments that were not typically available or feasible to audiometric technicians in the field.

A number of studies done involved the use of circumaural headphones in the measurement of HPD protection (Michae1, Kerlin, Bienvenue, Prout, and Shampan, 1976; Edwards et al., 1978). Although this method is considered. to be a reliable alternative to the ANSI method for use in the work place, it still is not practical for field use as it requires specially designed headphones which are not commercially available, and which are not calibrated for use with industrial audiometers. Other studies support the use of standard audiometric equipment and earphones for the measurement of HPDs, equipment that is readily available to audiometric technicians in the field (Berger, 1986, 1988). Although referred to by Berger as the best method for real world testing, there is not sufficient data for this method 
to be considered a reliable alternative to the standard ANSI procedure (Berger, 1984, 1986, 1988). However, there are still some problems associated with this method, problems that account for its lack of acceptance by industry. Berger (1986) lists these problems as follows:

1) only insert type HPDs can be tested, 2) the earphone may lay on the HPD breaking the seal of the fit or pushing the earplug further into the ear, 3) the earphone may cause a distortion of the concha by sitting on the pinna, and 4) the earphone may touch the earplug causing the earplug to create its own vibrations ( $\mathrm{p}$. 78).

In 1988 Gaier investigated two alternative methods to the ANSI procedure for the measurement of the "goodness of fit" of HPDs. In one condition she used standard audiometric equipment and headphones, and in the other she used a specially designed support placed between the conventional audiometer headphone and the subject's ear. The support was intended to overcome some of the aforementioned problems associated with standard headphones.

Gaier tested the reliability of the headphone-withsupport method by measuring the attenuation of an inserttype HPD (E-A-R) using standard audiometric headphones and equipment on ten normal-hearing subjects. This study compared data obtained with the special headphone/support device to data obtained with the ANSI laboratory method. In the ANSI method attenuation was measured by means of onethira octave-band noise in sound field, and in the headphone/ support method pure tone stimuli through headphones. The only significant difference between the two methods was that 
of frequency. Specifically, at 3000 and $4000 \mathrm{~Hz}$ the headphones-with-support method produced higher attenuation values than did the ANSI method. This finding was consistent with earlier studies comparing attenuation determined by onethird octave-band stimuli to that obtained with pure tone stimuli (Webster, Thompson, and Beitscher, 1956; Waugh, 1974). The best correlation between the sound field method and the headphone/support method in the Gaier study was observed at 1000 and $2000 \mathrm{~Hz}$. Attenuation values obtained by the earphones-only method provided the highest correlation with that obtained with the ANSI method at $1000 \mathrm{~Hz}$. At higher frequencies the earphone-only method tended to overestimate attenuation (Berger, 1984; Gaier, 1988).

The results of the Gaier study suggested that the headphones-with-support method may be a reliable alternative to the ANSI method in industrial settings (Gaier, 1988). Gaier's stuoy investigated only one type of HPD. However, before recommending this methoo for field HPD evaluation in hearing conservation programs, further research on the methoo should involve other HPDs commonly used in industry. In the present study, two methods were used to determine the attenuation of four different manufactured inserttype HPDS: the standard ANSI procedure and the headphone/ support procedure used by Gaier (1988). This latter method was evaluated as a possible alternative to the standard ANSI procedure and the aforementioned use of standard audiometry headphones alone for field evaluation of HPDs. This stuoy 
also evaluated whether or not the headphone/support method was as reliable a procedure as the standard ANSI method in the measurement of attenuation for four different, inserttype HPDs. 
CHAPTER II

REVIEW OF THE LITERATURE

HISTORY OF STANDARDS DEVELOPMENT

Noise-induced hearing loss (NIHL) has become the most prevalent injury in industry today (U.S. Department of Health and Human Services/PHS, 1982). It has been estimated that 2.9 million industrial employees in the United States are exposed to 8-hour time-weighted averages (TWAs) of greater than 90 dBA (Berger, 1979). Because NIHL occurs over time rather than as a single incident, as with most industrial injuries, it often goes unnoticed and may not be identified until after the individual retires and is removed from the noisy environment. Hearing protection devices provide an effective and economic means by which hazardous noise levels may be reduced to acceptable levels when engineering and administrative controls are unfeasible or inadequate (U.S. Department of Health and Human Services/PHS, $1982)$.

The American National Standarảs Institute (ANSI) procedures for the measurement of hearing protection device attenuation came about as a result of increased hearing loss in those who worked near noise-producing jet engines in the 1940's and 1950's (Nixon, 1982). This created a need for the 
wearing of hearing protection devices among the noise-exposed workers. The need for standardization of methods used in the evaluation of hearing protectors arose when researchers, most of whom were members of the Acoustical Society of America, began to compare the data that they had acquired from different laboratories (Nixon, 1982). Not only did they find discrepancies in results, but many differences in the methods used from one laboratory to the other were discovered. This eventually led to the development of the first ANSI standard, the Real Ear Attenuation of Ear Protectors at Threshold, z24.22-1957 (revised in 1974 and 1984).

In 1970, the Occupational Safety and Health Act mandated that, based on an 8 -hour time-weighted average, hearing protection devices had to be provided by employers for all employees who were exposed to noise levels at or above $95 \mathrm{dBA}$, and that the devices had to be available for those employees exposed to noise levels of $85 \mathrm{dBA}$ or more (Regan, 1975). Major portions of this law went into effect in August, 1981. Employers were also required to provide training in the proper use and maintenance of the hearing protectors provided (Occupational Safety and Health Administration, 1983). The ANSI (S12.6-1984) standard is the most commonly used method by which this is accomplished today.

\section{CURRENT ANSI STANDARDS}

The current ANSI procedure involves the use of the Real Ear Attenuation at Threshold (REAT) method in sound field. 
This involves obtaining hearing thresholds in sound field in both an unoccluded condition (no earplugs) and in an occluded condition (with earplugs). The unoccluded threshold is then subtracted from the occluded threshold to determine the amount of attenuation provided by the earplugs. This method is the most commonly used by research 1aboratories (Nixon, 1982; Berger, 1984), and is considered to be the best methoo because of its suitability for evaluating all types of linear hearing protection devices (Riko and Alberti, 1983; Berger, j.988).

The ANSI REAT method also specifies the requirements for the testing environment, equipment, stimuli useỏ, ano. the procedure for fitting the hearing protection devices. Each of these will be subsequently discussed.

\section{Environment}

The ANSI S12.6-1984 standaro specifies that ambient room noise will not exceed a certain limit for each frequency to be tested. Table I shows the maximum amount of ambient noise allowed for each frequency to be tested. This requirement for the permissible ambient noise levels requires special acoustic rooms in which the earplug testing environment can be calibrated. 
TABLE I

MAXIMUM PERMISSIBLE AMBIENT NOISE LEVELS

FOR AUDIOMETRIC TESTING

Frequency, Hz

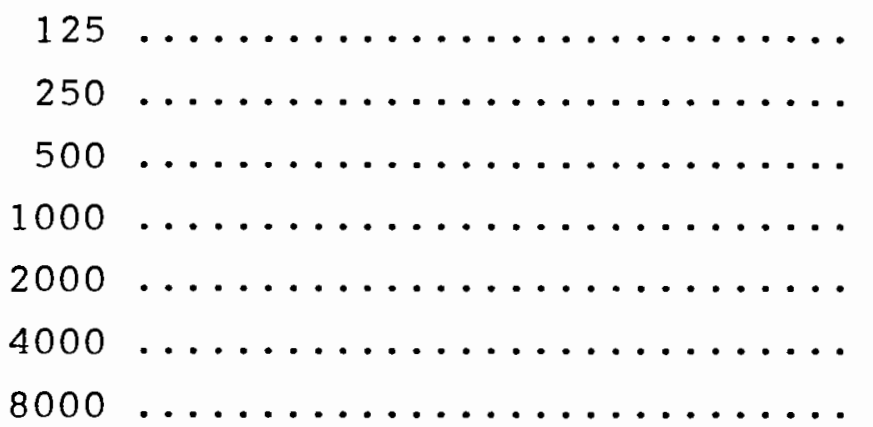

Octave Band, SPL* $20 \mathrm{uPa}$.

*Permissible ambient noise levels are in decibels re:

Stimulus

ANSI also specifies the type of stimuli to be used while testing attenuation characteristics of earplugs. The use of one-third octave-band noise stimuli in the frequency range of $250-8000 \mathrm{~Hz}$ is recommended. Recent studies have shown, however, that it may not be necessary to use all frequencies in that range (Fleming, 1980; Gaier, 1988; Berger, 1988). Based on their findings, these studies support the use of limiteo frequencies. Gaier (1.988) suggested a midfrequency tone $(1000 \mathrm{~Hz})$ as the stimulus, basing her recommendation on the fact that this is the frequency which proviod the best correlation between the "true" attenuation obtaineo using the ANSI methoo and the two alternative methods in her study. This frequency also has been mentioned as the stimulus of choice by Berger (1988). The reason for 
choosing a mid-frequency over a low or high frequency stimuIus is that REAT thresholds tend to increase with higher frequencies (Padilla, 1976), and lower frequencies presented via headphones cause a masking effect, a "covering up" of the test signal by physiological noises, resulting in elevateo thresholds (Rudmose, 1982; Riko and Alberti, 1983; Berger, 1986). The use of a limited frequency pure tone test also might allow workers to be tested on-site, in a shorter amount of time, with equipment already available, consisting of a conventional portable auoiometer with standard TDH-39 headphones. Such audiometers only produce pure tones, rather than the one-third octave-band noise stimuli used in the ANSI standard procedure.

The Need for An Alternative Procedure

ANSI lahoratory earplug attenuation tests produce much higher attenuation levels than those obtained in field tests (Michael et al., 1976; Regan, 1976; Riko and Alberti, 1983; Berger, 1982, 1984). Berger (1982) stated that this may be aue more to "subject selection, training, and motivation procedures practiced . . than with experimental method" (p. 299). Riko and Alberti (1983) referred to the requirements of special environments, equipment, and care of fitting of earplugs used in the laboratory studies, and Royster, Royster, and Cecich (1984) indicated that laboratory environments were not meant to be representative of actual worksites. Noting the deficiencies in the measurement 
procedures currently in use, Berger (1984, 1988) also indicated a need for a practical, portable procedure that can be used in the field.

\section{ALTERNATIVE METHODS}

Standard Headphones Alone

As indicated earlier, equipment that is readily available to audiometric technicians in the field consists of portable audiometers with standard TDH-39 headphones. Presently, there is not enough research data to support the use of this equipment as a reliable alternative to the standard ANSI procedure for measuring attenuation. Problems associated with the use of standard headphones are mentioned in a variety of studies (Michael et al., 1976; Regan, 1977; Berger, 1984, 1985, 1988). Three principal problems include: earphone pressure on the pinna creating a distortion of the fit of the earplug, (2) physical contact of the headphone to the earplug causing structural vibrations, and (3) pushing the earplug further into the ear. Conventional audiometer earphones therefore create sources of variance in earplug attenuation data.

\section{Circumaural Headphones}

The use of circumaural headphones as a means of measuring HPD protection was first introduced by Padilla (1976). This method was further developed and studied by Michael et al. (1976) in a study funded by NIOSH at 
Pennsylvania State University (Berger, 1984). This alternative procedure overcame some of the problems of the standard headphone alone procedure. The circumaural headphone does not sit directly on the pinna causing a distortion of the fit of the earplug, nor does it touch the earplug (even those with handles) causing the earplug itself to vibrate. It thus overcame problems associated with the earphone-only method. Studies have shown this method to be a reliable alternative to the standard ANSI procedure in the field (Edwards et al.. 1978). However, this method stil1 requires the use of nonstandard equipment that is not readily available for use in the field. The calibration differentials noted between the circumaural headphones and the TDH-39 headphones normally used with portable audiometers also makes this an invalid alternative to the ANSI method.

A third method of measuring HPD attenuation clinically has recently been evaluated using a probe tube microphone system (Traynor, Ackley, and Wiernsbowsky, 1989). There were some significant differences noted between the ANSI REAT method and the probe tube microphone method in this study. Also, the probe tube microphone method can only be realized in a clinical type setting, whereas the methoo to be evaluated in this study is designed for use in the field.

\section{Standard Headphone with Support}

The headphone/support method was proposed by Maurer in 1972 and evaluated by Gaier in 1988. This method involves 
the use of a standard TDH-39 headphone with a donut-shaped support placed between the ear and the headphone. The support is made of foam and plastic, with a hole cut in one side to fit around the pinna, avoiding both distortion of the pinna and disturbance of the fit of the earplug. The other side of the "donut" has a plastic cover with a hole cut to the size of the headphone cushion, so that the earphone can be centered over the ear. This eliminates most of the problems associated with the use of standard headphones alone without the expense of a difficult to obtain second set of headphones. It also allows the use of the standard audiometric headphones and audiometer which are already familiar to the industrial audiometric technician without additional calibrations.

In her study in 1988 , Gaier used three different methods to study one type of earplug. The three methods included. the standard ANSI method with one-third octave-band noise stimuli, the headphones alone with pure tones, and the headphones/support method with pure tones. The earplug tested was the $E-A-R$ polymer foam earplug. The attenuation values obtained using the standard ANSI procedure for this HPD, were comparable to those obtained by other researchers (Gaier, 1988). However, the attenuation values obtained by these studies were generally less than those values depicted by the manufacturers of the $E-A-R$ plug. These data are shown in Table II. 
TABLE II

MANUFACTURER AND FIELD ATTENUATION DATA

FOR THE E-A-R PLUG

\begin{tabular}{|c|c|c|c|c|c|}
\hline & & $1000 \mathrm{~Hz}$ & $2000 \mathrm{~Hz}$ & $3000 \mathrm{~Hz}$ & $4000 \mathrm{~Hz}$ \\
\hline \multicolumn{6}{|c|}{$\begin{array}{l}\text { Manufacturer } \\
\text { Data }\end{array}$} \\
\hline & Mean & $40.3 *$ & 41.8 & 44.6 & 45.3 \\
\hline & $\mathrm{SD}$ & 1.7 & 2.1 & 1.9 & 1.7 \\
\hline \multicolumn{6}{|c|}{ Gaier (1988) } \\
\hline & Mean & 32.17 & 33.83 & 41.03 & 41.40 \\
\hline & $\mathrm{SD}$ & 3.5 & 2.8 & 4.0 & 3.3 \\
\hline \multicolumn{6}{|c|}{$\begin{array}{l}\text { Michael et a1. } \\
\quad(1976)\end{array}$} \\
\hline & Mean & 34.3 & 32.9 & 39.9 & 40.6 \\
\hline & $\mathrm{SD}$ & 5.7 & 3.6 & 2.1 & 3.1 \\
\hline \multicolumn{6}{|c|}{ Berger (1.984) } \\
\hline & Mean & -- & 36.0 & -- & 40.3 \\
\hline & $\mathrm{SD}$ & -- & 3.7 & -- & 4.6 \\
\hline
\end{tabular}

*Attenuation values are expressed at each one-third octave-band center test frequency.

The lack of a significant difference between the "true" thresholds obtained using the ANSI method and the thresholds obtained using the headphone/support method at $1000 \mathrm{~Hz}$ and $2000 \mathrm{~Hz}$ in the Gaier study, support the headphones/support method as a possible option for use in the field to evaluate HPD attenuation. Further study is needed to determine the effectiveness of this method with other types of hearing protectors. 
The four types of HPDs to be evaluated in this study include: (1) V-51R, a preformed single-flanged earplug, (2) MAX, a preformed polymer-foam earplug, (3) a standard custom-molded earplug, and (4) a vented nonlinear custommolded earplug.

The questions to be answered in this study are:

1. Is the headphone/support method a practical, valid method for measuring the attenuation of a variety of inserttype HPDs when compared to the ANSI method?

2. Are reliable attenuation values obtained on testretest trials using the headphone/support method?

3. Does $1000 \mathrm{~Hz}$ continue to demonstrate the highest correlation between the ANSI method and the headphone/support method for the different types of HPDs measured? 


\section{CHAPTER III}

METHODS

SUBJECTS

Ten subjects with hearing thresholds within normal limits were used. Normal hearing was defined as thresholds between $-10 \mathrm{~dB} \mathrm{HL}$ and $20 \mathrm{~dB} \mathrm{HL}$ at $250,500,1000,2000,3000$, 4000, 6000, and $8000 \mathrm{~Hz}$, consistent with criteria in the American National Standard for the Measurement of the RealEar Attenuation of Hearing Protectors, ANSI S12,6-1984. The subjects were volunteers from the speech and Hearing sciences program at Portland State University and ranged in age from 18 to 41 years-of-age.

\section{INSTRUMENTATION}

All instrumentation for sound field testing was set up, calibrated, and used in accordance with the procedures outlined in the ANSI (1984) standard. Testing was done in a sound treated room (International Acoustics Corporation, Model 1403) located at Portland State University. This dual room test suite provided the controlled environment which meets the permissible noise levels, as specified in ANSI S12.6-1984. All requirements of test sounds, sound field characteristics, test apparatus, signal source, control 
circuits, loudspeakers, head-positioning device, and distortion, as specified in the ANSI standard, were met.

As specified in the ANSI standard, a calibrated audiometer (Beltone, Model 2000) was used for all threshold measurements. A broadband white noise was produced by the left channel of the audiometer and routed through a Bruel and Kjaer one-third octave-band pass filter (Series 1616) for the sound field noise stimulus. Noise stimuli were amplified by a Crown amplifier (Model D-75), and presented via two Realistic (MC 1800) loudspeakers.

A specially designed foam support device was superimposed on the headphones for the second method evaluated. A prototype of this device was first compared with the ANSI laboratory method by Gaier in 1988. The support surrounded the pinna keeping the headphone from distorting the fit of the earplug. Modifications in the prototype involved trimming away the plastic portion so that the headphone cushion was seated within the plastic and rested directly on the foam, but not in contact with the pinna (see Figure 1). This eliminated the double cavity created by the plastic face of the device, and decreased the risk of the diaphragm of the earphone being placed improperly over the center of the headphone/support device. This physical change did not alter the volume of the space between the earphone and the ear.

The earplugs evaluated in this study were: (1) a standard custom-molded earplug, (2) MAX, a preformed polymer-foam earplug, (3) V-51R, a preformed single-flanged earplug, and (4) a vented nonlinear custom-molded earplug. These earplugs were chosen based on their common usage in industry (see Figure 2). 


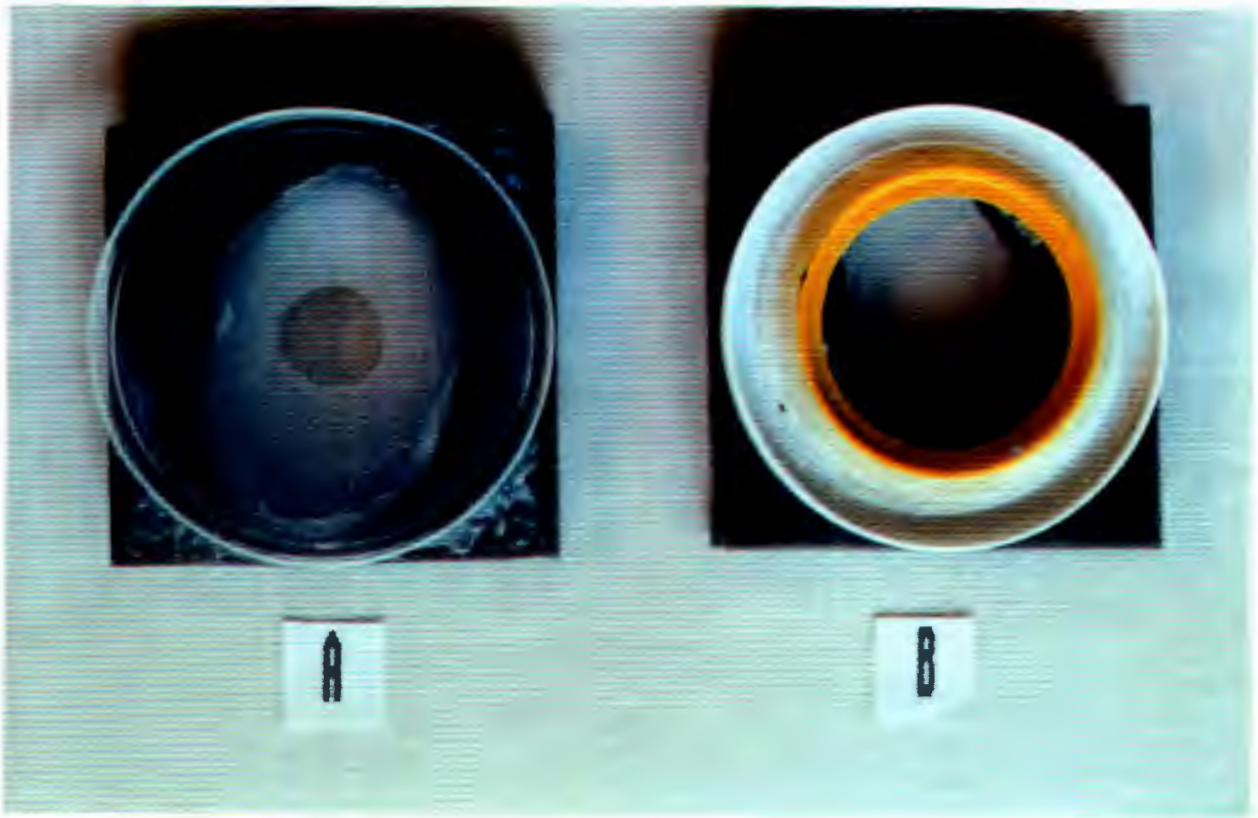

Figure 1. Headphone/support device A, used by Gaier; headphone/support device B, modified version used in current study.

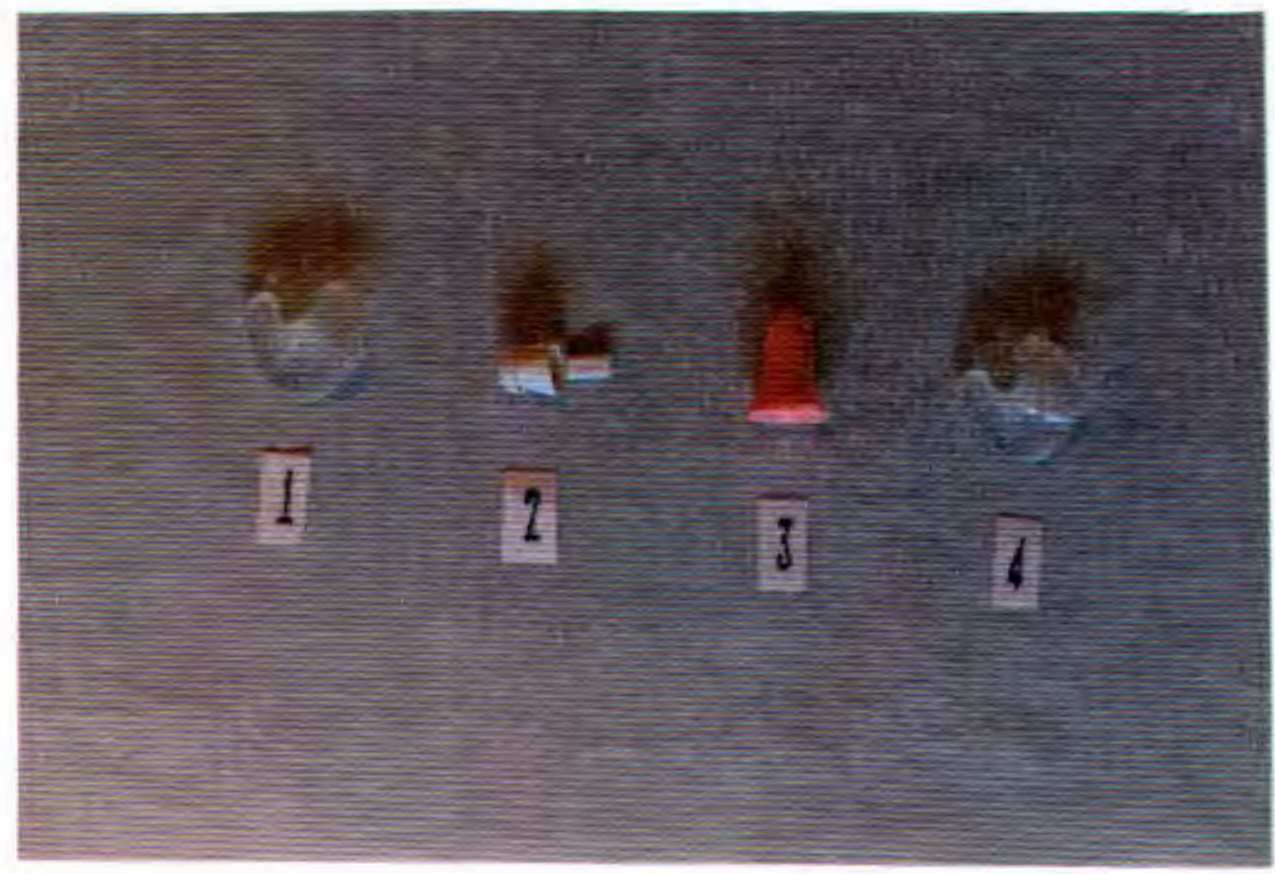

Fiqure 2. Earplugs used in current study: 1--solid custom-molded, 2--MAX, 3--V-51R, 4-vented custom-molded. 
PROCEDURE

Each earplug was assessed by obtaining three sets of occluded and unoccluded real-ear thresholds. These thresholds were obtained using two test methods: (1) one-third octave-band noise stimuli presented in sound field, and (2) pure tone stimuli were delivered via TDH-39 earphones mounted in MX-41/AR cushions under the headphone/support device. Testing was done monaurally. To eliminate the nontest ear from participating an $E-A-R$ earplug was inserted into the nontest ear, which was then covered with a Flenta "Silenta" earmuff (Model 0800).

Test stimuli consisted of one-third octave-bands of noise centered at $1000,2000,3150$, and $4000 \mathrm{~Hz}$, and pure tone stimuli presented at $1000,2000,3000$, and $4000 \mathrm{~Hz}$. Subject hearing thresholds were obtained using 1 dB steps in a modified Hughson-Westlake procedure (Newby, 1979).

Prior to threshold measurement, subjects were shown how to insert the earplugs according to the manufacturer's instructions. The nontest ear was then occluded using the E-A-R plug and earmuff. An unoccluded sound field threshold for the test ear was then obtained using the narrow band noise stimuli. The subject was then asked to insert the first earplug to be evaluated. During insertion, a white noise at a level of $70 \mathrm{~dB}$ SPL was introduced into the room so that the subject could jucge the point of maximum 
attenuation during insertion. The fit of the earplug was then visually checked by the examiner. Thresholds were then obtained in sound field with the test ear occluded.

Following this, the Flents "Silenta" earmuff was removed from the nontest ear and the headphones were placed on the subject. The support was placed around the test ear and the headphone cushion seated in the plastic face of the support. Occluded thresholds were then obtained. After this the earplug was removed and unoccluded thresholds, with the support still in place, were obtaineot.

This procedure was repeated twice for each of the earplugs tested for a total. of three trials per plug. The procedure was designed so that the earplug would not be disturbed for each set of measures, thereby avoiding distortion of the fit. The earplugs were removed and reinserted between each set of measures.

Attenuation in decibels was determined for each earplug at each frequency for each subject by subtracting the unoccluded threshold from the occluded threshold. 
CHAPTER IV

RESULTS AND DISCUSSION

RESULTS

Two different methods were used to evaluate the amount of attenuation provided by four different insert-type hearing protection devices. The two methods included the standard ANSI method of using one-third octave-bands of noise stimuli presented in sound field and an alternative method using pure tone stimuli presented under standard audiometric headphones with a supporting device inserted between the headphones and the ear. Both methods employed a real-ear-at-threshold (REAT) procedure for determining occluded and unoccluded thresholds at four frequencies.

The one-third octave-band stimuli were centered at frequencies of $1000,2000,3150$, and $4000 \mathrm{~Hz}$ for the ANSI sound field method; pure tone stimuli were $1000,2000,3000$, and $4000 \mathrm{~Hz}$ for the headphone/support method. Hearing thresholds were obtained in 1 dB steps using a modified Hughson-Westlake procedure. The unoccluded thresholds were subtracted from the occluded thresholds to determine the amount of attenuation provided. The mean attenuation values obtained for each method are listed in Tables III and IV. (Thresholds for each subject are given in 
Appendix $B$ and average attenuation values for each earplug are given in Appendix C). Means and standard deviations from Gaier's study (1988) are also included for comparison in Tables III and IV. Mean attenuation across trials for each plug in the headphone/support condition is plotted in Figure 3, p. 24; the mean attenuation across trials for each plug in the sound field condition is plotted in Figure 4, p. 25 .

TABLE III

A COMPARISON OF TRIAL MEANS AND STANDARD DEVIATIONS ACROSS FREQUENCIES FOR EACH EARPLUG EVALUATED WITH THE SOUND FIELD METHOD

\begin{tabular}{|c|c|c|c|c|}
\hline & $1000 \mathrm{~Hz}$ & $2000 \mathrm{~Hz}$ & $3000 \mathrm{~Hz}$ & $4000 \mathrm{~Hz}$ \\
\hline \multicolumn{5}{|l|}{ MAX } \\
\hline Mean & 31.86 & 33.27 & 42.81 & 44.83 \\
\hline$S D$ & 5.01 & 6.54 & 3.52 & 4.51 \\
\hline \multicolumn{5}{|l|}{$V-51 R$} \\
\hline Mean & 18.48 & 24.94 & 27.41 & 25.33 \\
\hline SD & 8.70 & 5.96 & 6.20 & 5.18 \\
\hline \multicolumn{5}{|c|}{ Custom-Molded } \\
\hline Mean & 8.10 & 16.38 & 24.10 & 23.46 \\
\hline $\mathrm{SD}$ & 3.94 & 5.33 & 3.86 & 5.54 \\
\hline \multicolumn{5}{|c|}{$\begin{array}{l}\text { Custom-Molded } \\
\text { w/Vent }\end{array}$} \\
\hline Mean & 8.29 & 16.77 & 24.23 & 23.34 \\
\hline SD & 5.36 & 6.05 & $4 \cdot 16$ & 5.57 \\
\hline \multicolumn{5}{|c|}{$\begin{array}{l}E-A-R \\
\quad(\text { Gaier, 1988)* }\end{array}$} \\
\hline Mean & 32.17 & 33.83 & 41.03 & 41.40 \\
\hline$S D$ & 3.50 & 2.77 & 4.03 & 3.30 \\
\hline
\end{tabular}

*Gaier's E-A-R data for this method are included for comparison purposes. 
TABLE IV

A COMPARISON OF TRIAL MEANS AND STANDARD DEVIATIONS ACROSS FREQUENCIES FOR EACH EARPLUG EVALUATED WITH THE HEADPHONE/SUPPORT METHOD

\begin{tabular}{|c|c|c|c|c|}
\hline & $1000 \mathrm{~Hz}$ & $2000 \mathrm{~Hz}$ & $3000 \mathrm{~Hz}$ & $4000 \mathrm{~Hz}$ \\
\hline \multicolumn{5}{|l|}{ MAX } \\
\hline Mean & 34.63 & 34.54 & 42.37 & 46.97 \\
\hline$S D$ & 6.54 & 2.41 & 2.13 & 4.12 \\
\hline \multicolumn{5}{|l|}{$V-51 R$} \\
\hline Mean & 19.16 & 24 & 30.86 & 27.14 \\
\hline$S D$ & 7.48 & 5.42 & 5.59 & 5.20 \\
\hline \multicolumn{5}{|c|}{ Custom-Molded } \\
\hline Mean & 8.27 & 14.73 & 23.14 & 22.81 \\
\hline $\mathrm{SD}$ & 6.13 & 6.38 & 4.51 & 5.27 \\
\hline \multicolumn{5}{|c|}{$\begin{array}{l}\text { Custom-Molded } \\
\text { w/Vent }\end{array}$} \\
\hline Mean & 7.48 & 14.16 & 23.59 & 24.57 \\
\hline $\mathrm{SD}$ & 4.75 & 5.52 & 4.42 & 3.38 \\
\hline \multicolumn{5}{|c|}{$\begin{array}{l}\text { E-A-R- } \\
\quad(\text { Gaier, 1988)* }\end{array}$} \\
\hline Mean & 30.93 & 32.50 & 43.97 & 45.27 \\
\hline $\mathrm{SD}$ & 4.06 & 3.52 & 2.93 & 4.93 \\
\hline
\end{tabular}

*Gaier's E-A-R data for this method are included for comparison purposes. 


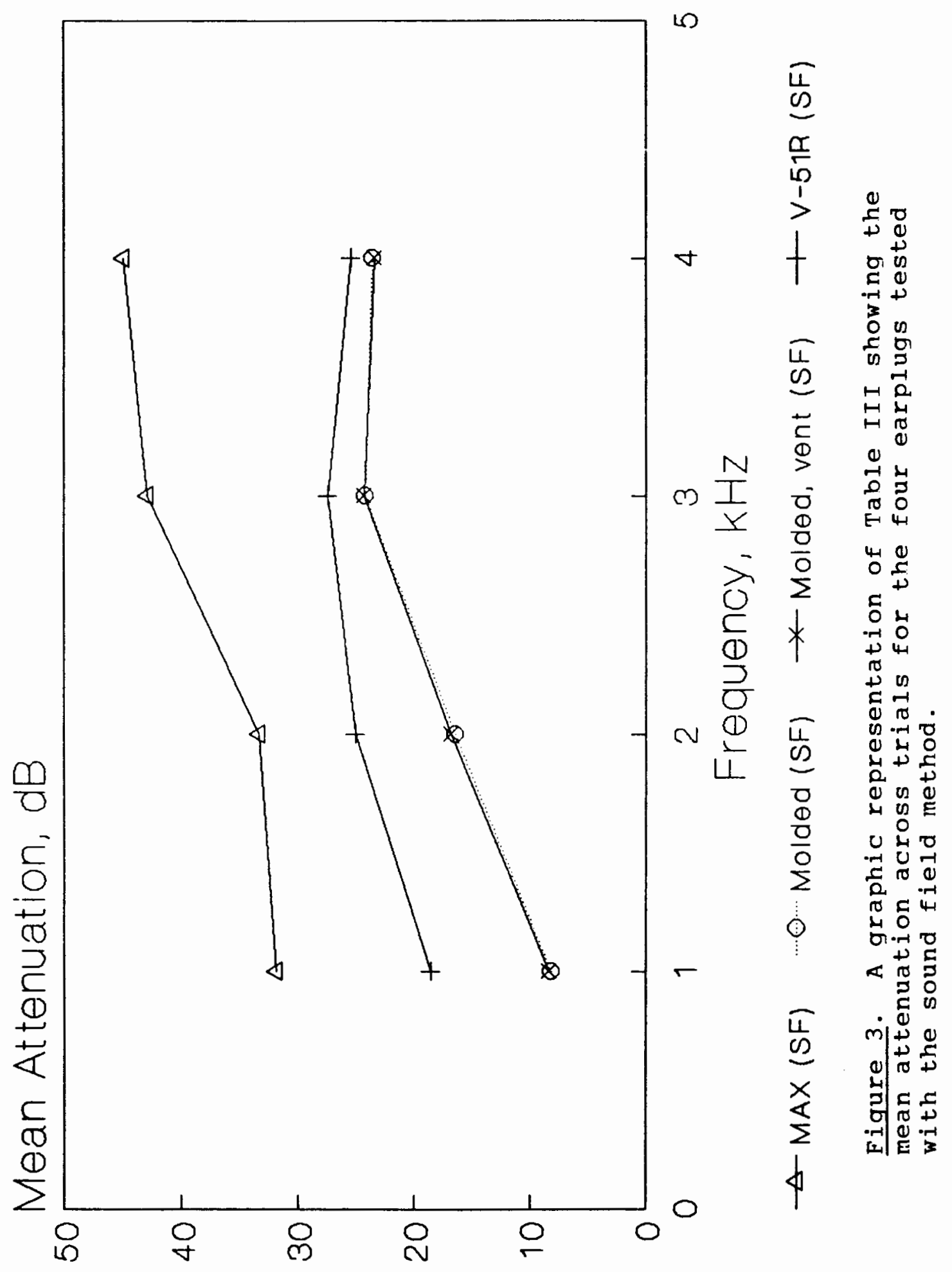




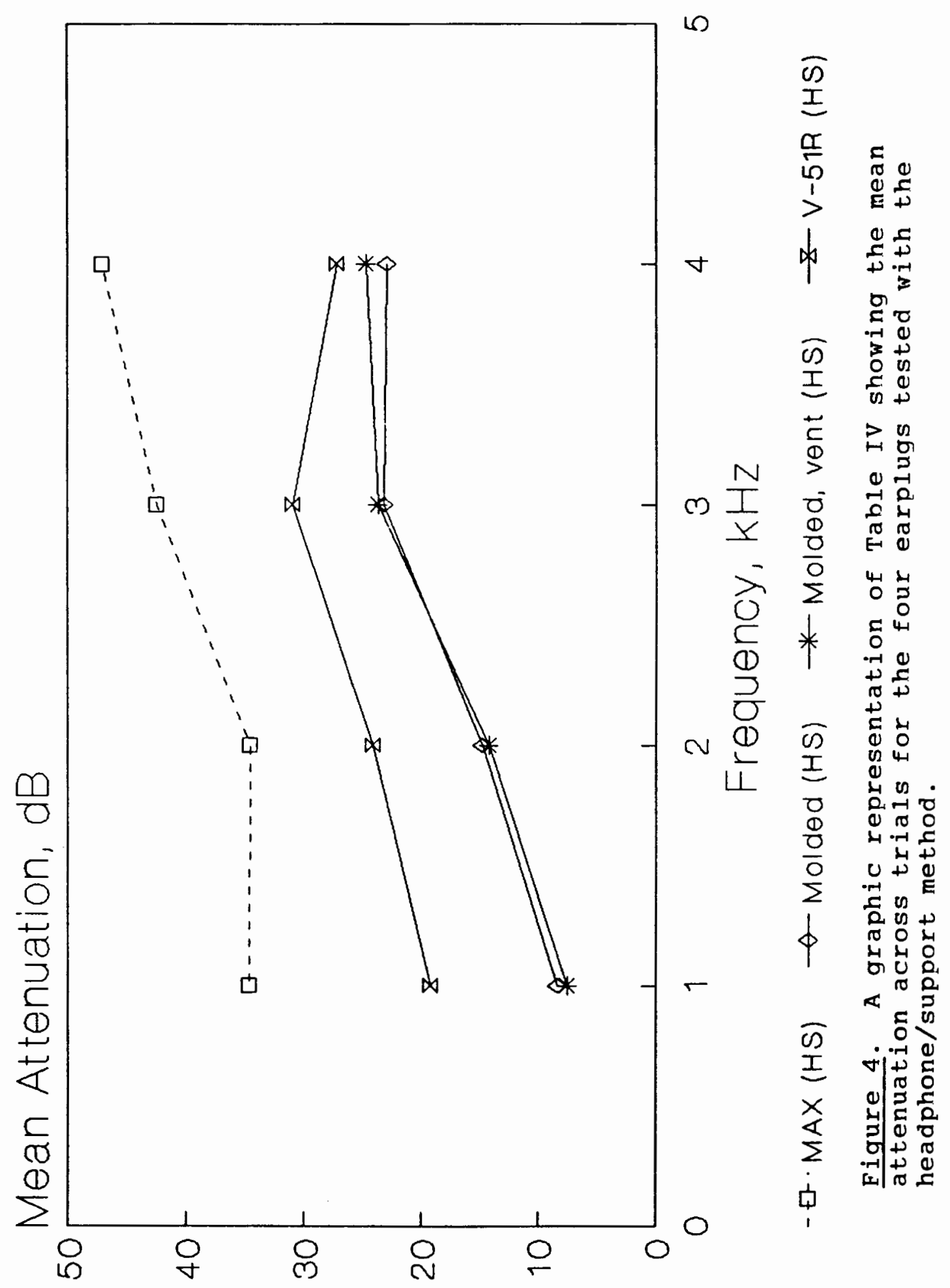


When comparing the sound field method to the headphone/ support method for each plug separately some interesting trends appear (see Figures 5 through 8 , pp. 28-31). Al1 of the plugs produced higher attenuation values at $3000 \mathrm{~Hz}$ and $4000 \mathrm{~Hz}$ than at $1000 \mathrm{~Hz}$ and $2000 \mathrm{~Hz}$. This supports the findings of Gaier (1988). The amount of attenuation provided by the V-51R earplug is considerably less than that provided by the MAX earplug. The custom-molded earplugs produced approximately equal amounts of attenuation for both methods. Both custom-molded earplugs provided significantly less attenuation than the $V-51 R$ and the MAX earplugs. A multivariate analysis of variance (MANOVA) for repeated measures using four within-subject factors (earplug, method, frequency, and trial) was used to analyze the attenuation data. The results of this analysis revealed statistically significant main effects of frequency $(p<.001)$ and plug type $(p<.001)$. This indicates that attenuation values differed for different frequencies and for different plugs. Follow-up t-tests for differences between frequencies demonstrated statistically significant differences between all of the frequencies tested except between $3000 \mathrm{~Hz}$ and $4000 \mathrm{~Hz}$. The effect of method was not significant $(p>.1)$ indicating that attenuation values obtained using the ANSI method did not differ significantly from those obtained using the headphone/support method. The greatest difference between methods was only $3.5 \mathrm{~dB}$ at $3000 \mathrm{~Hz}$ despite the fact that the center frequency for the narrow 
band noise was different $(3150 \mathrm{~Hz})$ from the pure tone $(3000 \mathrm{~Hz})$. The interaction between trial and method was statistically significant $(p<.01)$ indicating that a difference across trials was dependent upon the method used, holding all other factors constant. Pearson correlation coefficients for across trial comparisons are given in Appendix D. No other interactions were significant. 


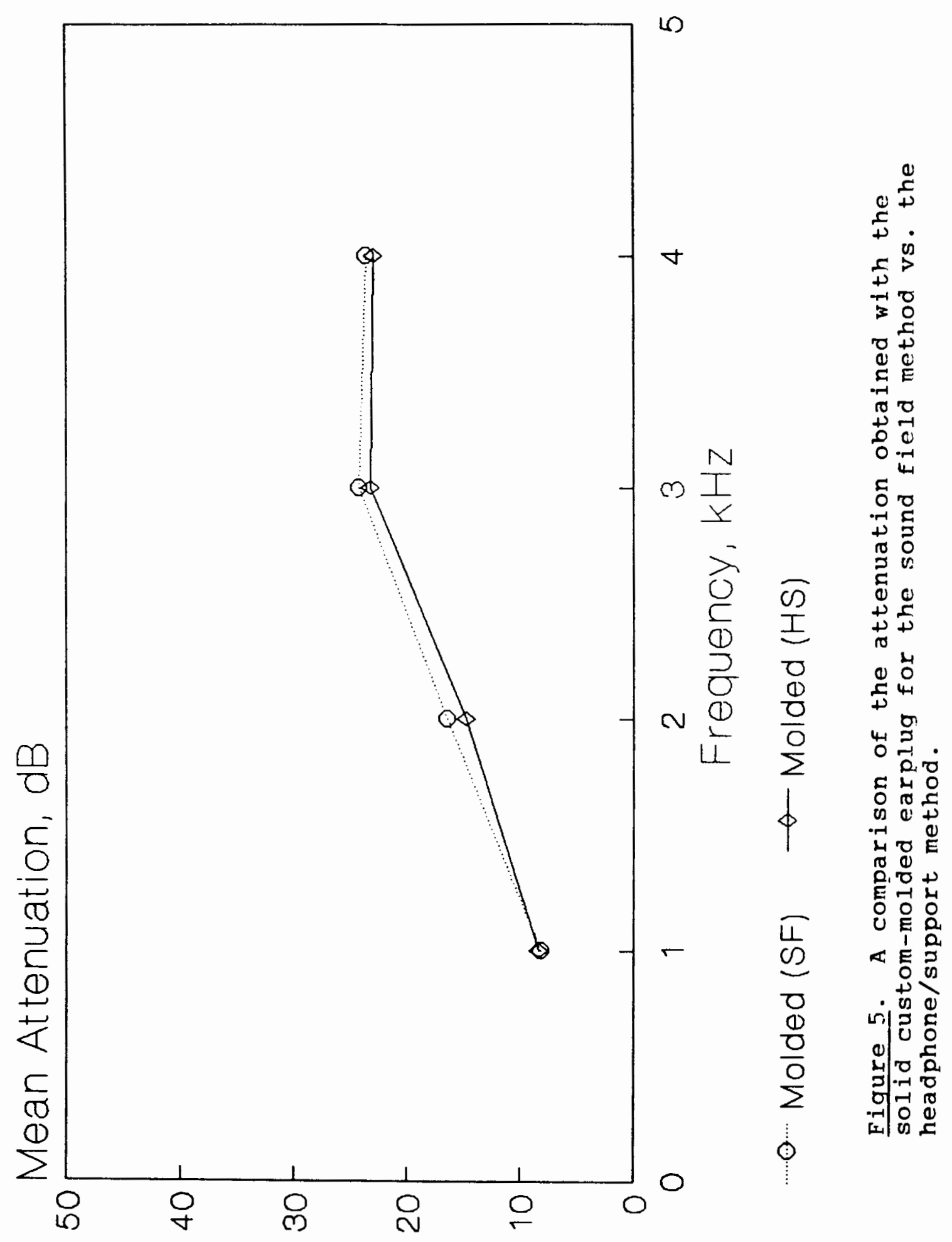




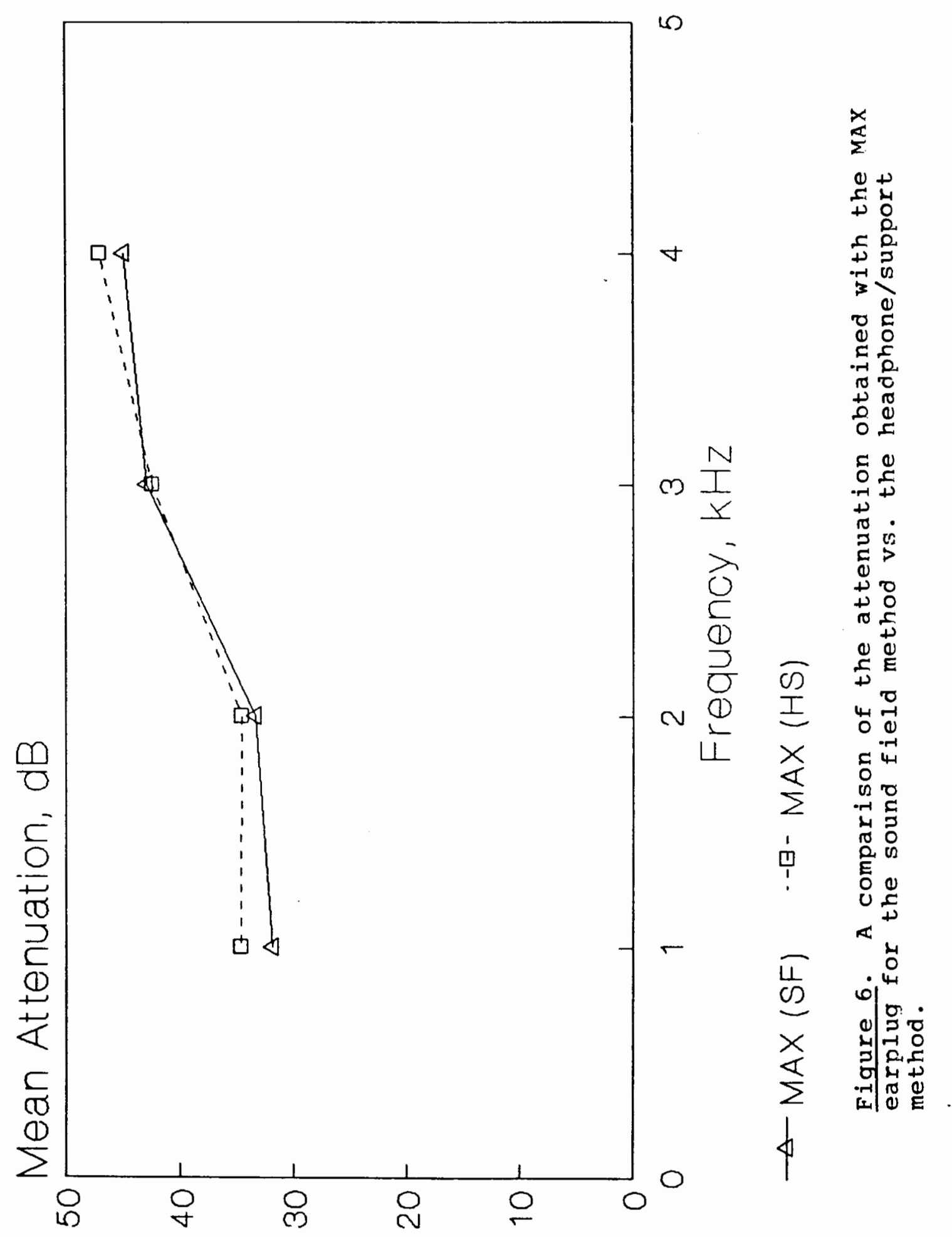




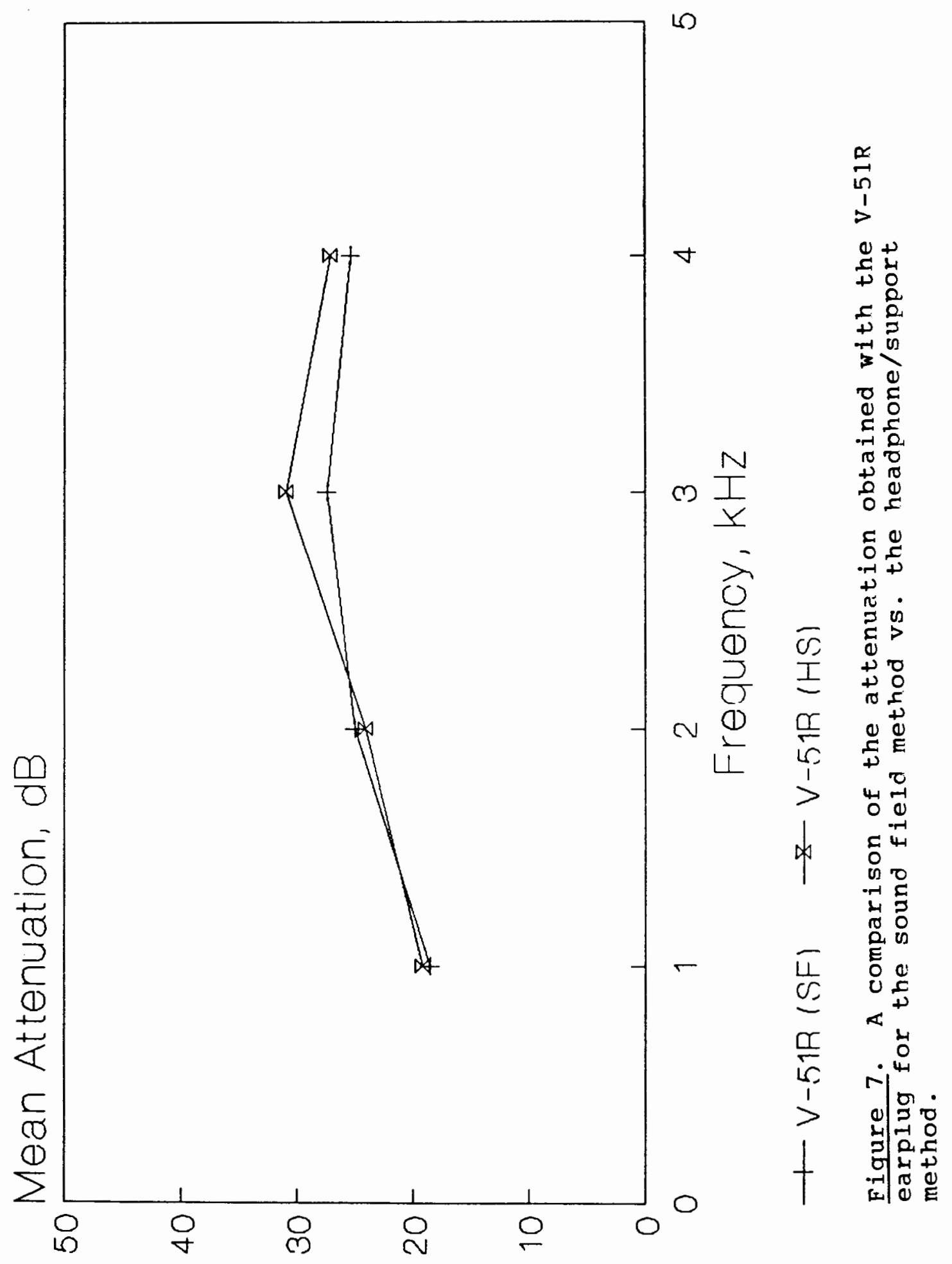




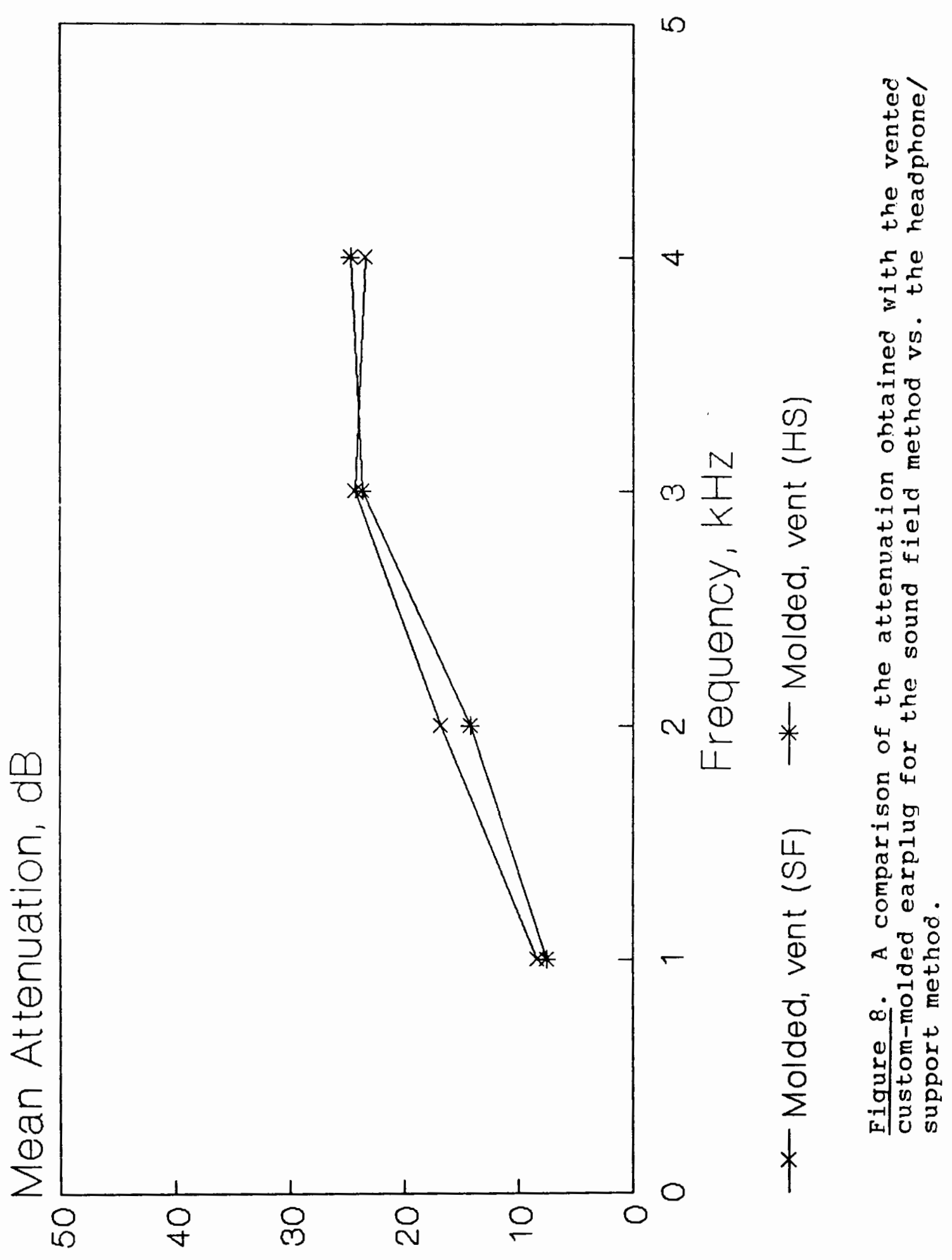


Since there is no statistically significant difference $(p>.02)$ at any frequency between the average attenuation for the custom-molded earplug and the custom-molded plug with a resonance decay vent, they will be considered as only one type of earplug and referred to as the custom-molded earplugs. Gaier's results indicated that the headphone/support method may be a reliable method for field testing of the E-A-R earplug. This study showed reliability across a variety of HPDs. Reliability here was indicated by correlation analysis across the three trials for each method $(r>.70)$. Reliability was evaluated for each earplug and each frequency separately. The results of this study revealed that there was a significant difference across trials for the headphone/ support method, but not the sound field method. These differences are plotted in Figure 9. 


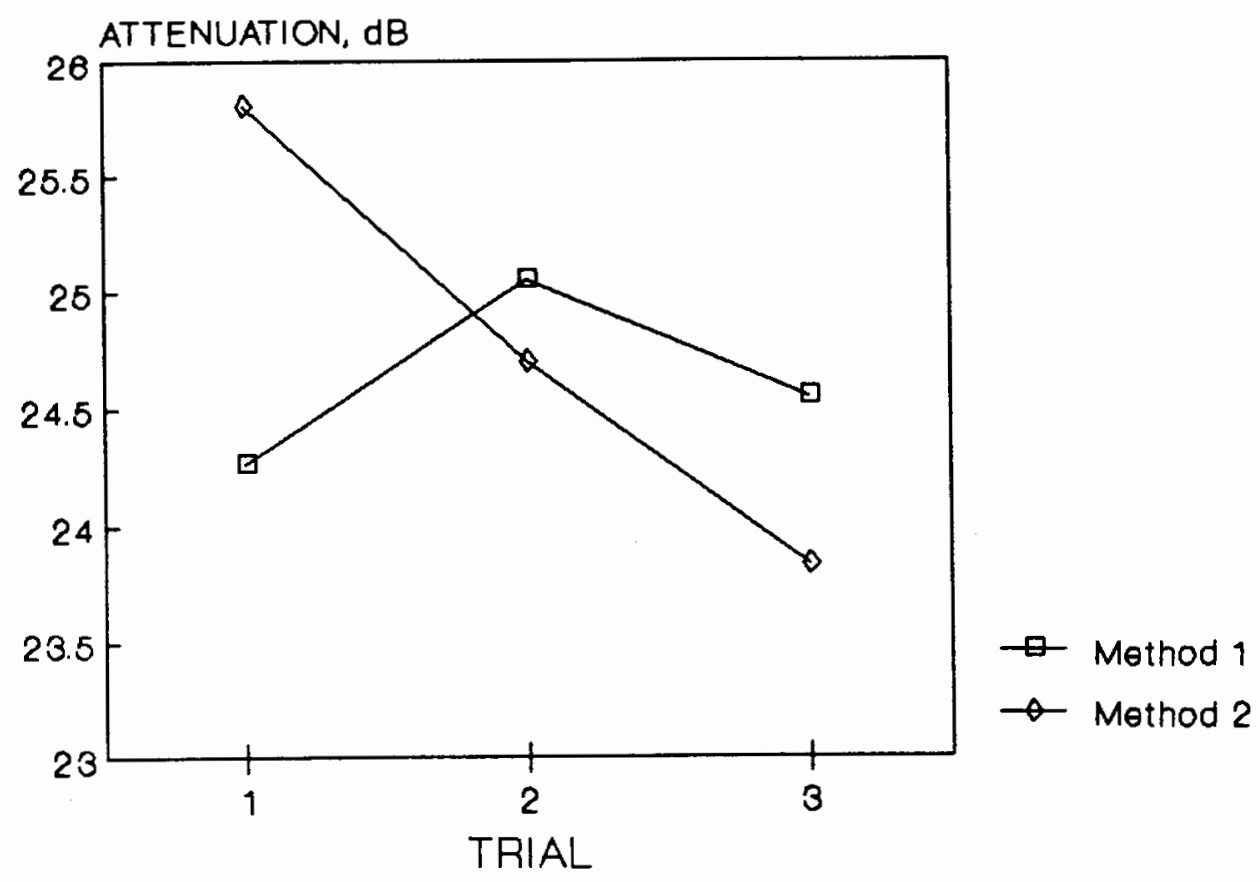

Figure 9. A graphic representation of the difference in attenuation obtained across trials for the sound field method (1) and the headphone/support method (2).

Differences in the reliability across trials were dependent upon plug type and frequency. All plugs were reliable across trial and method at $1000 \mathrm{~Hz}$. The custommolded plugs were less reliable at the other three frequencies and less so for the sound field method than the headphone/ support method. The MAX earplug was also reliable across trials at $1000 \mathrm{~Hz}$ with the headphone/support method $(r=.70)$ and the sound field method $(r=.87)$ and less reliable across trials for the other three frequencies. Although the V-51R provided less overall attenuation than the MAX earplug, it provided the highest correlation coefficient $(r=.97)$ at $1000 \mathrm{~Hz}$ and was consistently more reliable across trial, 
method and frequency than the MAX or the custom-molded earplug across trials at any frequency. This indicates that for any given earplug tested, $1000 \mathrm{~Hz}$ is the only frequency that proves to be consistently reliable across repeated trials. Table $V$ shows the average reliability for each earplug and frequency for the two methods tested.

TABLE V

AVERAGE TEST-RETEST RELIABILITY OF THE SOUND FIELD METHOD AND THE HEADPHONE/SUPPORT METHOD BY FREQUENCY AND PLUG TYPE

AS DERIVED FROM THE PEARSON CORRELATION COEFFICIENTS

\begin{tabular}{ccccc}
\hline Plug & $1000 \mathrm{~Hz}$ & $2000 \mathrm{~Hz}$ & $3000 \mathrm{~Hz}$ & $4000 \mathrm{~Hz}$ \\
\hline 1 & Sound Field \\
\hline 2 & .70 & .49 & .75 & .75 \\
3 & .84 & .53 & .75 & .54 \\
4 & .89 & .74 & .74 & .66 \\
& .77 & .63 & .62 & .62 \\
\hline 1 & .76 & .68 & .58 & .46 \\
2 & .71 & .34 & .31 & .21 \\
3 & .78 & .67 & .74 & .32 \\
4 & .82 & .64 & .32 & .24 \\
\hline
\end{tabular}

DISCUSSION

The sound field method of measuring attenuation used in this study was completed in accordance with the Method for the Measurement of the Real-Ear Attenuation of Hearing Protectors (ANSI S12.6-1984), and is considered the "true" attenuation 
for the HPDs evaluated. The attenuation values obtained with this method in this study tend to be lower than those reported by the manufacturers for their products. As stated previously, manufacturer attenuation values tend to be higher than those obtained in most laboratory studies, a factor that has been associated with the use of experienced subjects by the manufacturers (reported in a prepublication article by Gaier, Maurer, and Dolan, 1990).

The current study attempted to answer three questions:

1. Is the headphone/support method a practical, valid method for measuring the attenuation of a variety of inserttype HPDs when compared to the ANSI method?

2. Are reliable attenuation values obtained on testretest trials using the headphone/support method?

3. Does $1000 \mathrm{~Hz}$ continue to demonstrate the highest correlation between the ANSI method and the headphone/support method for the different types of HPDs measured?

In answer to the first question, a comparison between the "true" attenuation values obtained with the sound field method and the attenuation obtained with the headphone/ support method revealed similar results for all of the HPDs tested.

No significant difference vas seen at $4000 \mathrm{~Hz}$ between the sound field method and the headphone/support method in contrast to Gaier who found that the headphone/support device tended to overestimate attenuation at this frequency (1988). 
Since there is a higher probability of encountering a hearing loss at $4000 \mathrm{~Hz}$ in industrial populations, testing goodness of fit at that frequency may be contraindicated.

There were no significant differences across trials when comparing the methods to each other, further confirming the headphone/support method as a valid alternative to the ANSI method. There were, however, significant differences between trials when comparing within methods for the headphone/support method for $2000 \mathrm{~Hz}, 3000 \mathrm{~Hz}$, and $4000 \mathrm{~Hz}$ (see Pearson correlation coefficients in Appendix D). This variability in the headphone/support method may be accounted for by the fact that the correlation coefficients were obtained by collapsing the frequencies together and holding them constant while evaluating the across trial attenuation values. There was a significant effect of frequency, and this may have been great enough to affect the trial comparisons when held constant. Also, pure tone stimuli were used in the headphone/support method. These stimuli were presented under headphones with an insert device which created a cavity between the sound source and the ear which was not present in the sound field condition.

All statistical analyses indicate that $1000 \mathrm{~Hz}$ continues to provide the best correlation and greatest reliability between methods, regardless of the earplug measured or the amount of attenuation obtained. If industrial audiometric technicians were to employ a screening procedure at $1000 \mathrm{~Hz}$ for the employees they test, as suggested by Berger (1984, 
1988), then the headphone/support method would be considered a reliable alternate method to the ANSI or headphones alone methods.

Greater standard deviations were found in this study than in the Gaier study for both of the methods evaluated. Several explanations may be possible for this. All of the subjects used in this study were female. This is in contrast to the subject populations which have been used in previous studies. Several of the subjects in this study had tiny ear canals as evidenced by their difficulty in fully inserting the MAX and $V-51 R$ earplugs. Another possible explanation may be inadequately fitting custom-molded earplugs creating a path for sound leakage around the earplug. This problem with custom-molded plugs was noted earlier by Berger (1988).

In answer to the questions posed by this study, the findings indicate that the headphone/support method may be a practical, valid alternative to the ANSI method for measuring the attenuation of a variety of insert-type HPDs. Reliability was good when comparing across methods and was consistent at $1000 \mathrm{~Hz}$ for all HPDs tested, but varied at the other three frequencies within the headphone/support method. Further research should be directed toward a field investigation of the method on industrial employees to determine the validity of the device in background noise and in industrial settings. 
CHAPTER V

SUMMARY

The need for hearing protection in industry has evolved from the growing awareness of the detrimental effects of noise on hearing and recent legislation enacted to protect the hearing of noise-exposed employees through the use of hearing conservation programs. In 1 ieu of expensive or impractical engineering and administrative controls, personal hearing protection devices (HPDs) are considered to be the most practical and effective means of protecting employees from the damaging effects of noise in industry today.

In order to assure that the best possible attenuation (noise reduction) is obtained with HPDs provided, some form of measurement procedure for the measurement of the attenuation provided by the HPDs needed to be developed. This resulted in the development of the ANSI Real Ear Attenuation of Ear Protectors at Threshold (Z24.22, 1957, revised in 1974 and 1984). The final revision ANSI S12.6-1984 is the method currently used in the laboratory for the measurement of HPDs. This method requires the use of one-third octavebands of noise stimuli in sound field and is impractical for use in field measurements, where measurements of "real world" attenuation are needed to determine the amount of actual protection provided to workers on the job. Laboratory studies 
using the ANSI method produce results that tend to be much higher than those obtained in field studies. This prompted the need for a method that can be tested in the field that is a valid and reliable alternative to the ANSI method. The purpose of this study was to validate the effectiveness of an alternative method of measuring HPD attenuation. The method makes use of standard portable audiometers and TDH-39 headphones with an experimental headphone/support device made of easily obtained materials. This method was found by Gaier in 1987 to be an effective method for measuring the attenuation of the E-A-R insert-type earplug.

The present study compared the experimental method, employing pure-tone stimuli, to the ANSI method, which uses one-third octave-bands of noise in sound field. Four earplugs commonly used in industry were tested for goodness of fit on ten subjects with normal hearing thresholds. Significant differences were not found between the ANSI and the experimental method at any of the frequencies tested. Significant differences $(p<.001)$ were found between frequencies, depending upon the plug type. Significant differences $(p<.01)$ were found across trials for the headphone/support method at all frequencies except $1000 \mathrm{Kz}$.

These results indicate that this method is a valid alternative to the ANSI method for further research in the field, but is most reliable at one test frequency, $1000 \mathrm{~Hz}$. A field study of the headphone/support method for the determination of "real world" attenuation provided by insert-type 
hearing protection devices is indicated to determine if the laboratory results found in this study, or those of the Gaier study, carry over into field use. 


\section{REFERENCES}

Abel, S. M., Alberti, P. W., and Riko, K. (1982). User fitting of hearing protection: Attenuation results. In P. W. Alberti (ed.), Personal hearing protection in Industry. New York: Raven Press.

ANSI (1957). ANSI Z24.22-1957. American national standard for the measurement of real-ear attenuation of ear protectors at threshold. New York: American National Standards Institute.

ANSI (1974). ANSI S3.19-1974. American national standard method for the measurement of real-ear protection of hearing protectors and physical attenuation of ear muffs. New York: American National Standards Institute.

ANSI (1984). ANSI S12.6-1984. American national standard method for the measurement of the real-ear attenuation hearing protectors. New York: American National. Standard Institute.

Behar, A. and Mihai, A. (1984). A signal generator for testing of hearing protectors. Applied Acoustics, $\mathrm{n} . \mathrm{v} ., 395-403$.

Berger, E. H. (1979). The hearing conservation amendment. E-A-RLog 11.

(1982). Laboratory estimate of the real worlo performance of hearing protectors. In P. W. Alberti (ed.), Personal hearing protection in industry, pp. 299-313. New York; Raven Press.

(1983). Using the NRR to estimate the real world performance of hearing protectors. Sound and vibration, $\underline{17}(1), 12-18$.

(1984). Assessment of the performance of hearing protectors for hearing conservation purposes. Noise and Vibration Control Worldwide, 15(3), 75-81.

(1985). Workers' compensation for occupational hearing loss. E-A-RLOQ 15. 
(1985). A new hearing protector attenuation standard--Ansi S12.6. E-A-RLoq 16.

(1986). Methods of measuring the attenuation of hearing protection devices. Journal of the Acoustical Society of America, 76(6), 1655-1687.

(1988). Can real-world hearing protector attenuation be estimated using laboratory data. Sound and Vibration, $\underline{2} 2(12), 26-31$.

(1988). Use of circumaural and supra-aural earphones to measure the real-ear attenuation of earplugs. American Industrial Hygiene Conference, Abstract No. 39.

Berger, E. H. and Kerivan, J. E. (1982). Inter-laboratory variability in the measurement of hearing protection attenuation. Sound and Vibration, n.v., 14-19.

Billings, B. L. (1978). Performance characteristics of two noise-excluding audiometric headsets. Sound and vibration, $\mathrm{n} . \mathrm{v} ., 20-23$.

Crawford, D. R. and Nozza, R. J. (1981). Field performance evaluation of wearer-molded ear inserts. American Industrial Hygiene Conference, Absrtact No. 398 .

Edwards, R. G., Hauser, W. P., Moiseev, N. A., Broderson, A. B., and Green, W. W. (1978). Effectiveness of earplugs as worn in the workplace. Sound and Vibration, n.v., 112-122.

Fleming, R. M. (1980). A new procedure for field testing of earplugs for occupational noise reduction.

Doctoral dissertation, Harvard School of Public Health.

Gaier, I. J. (1988). A comparison of three methods for measuring the attenuation provided by insert-type hearing protective devices. M.S. thesis, Portland state University.

Gaier, L. J., Maurer, J. F., and Dolan, T. G. (1990). A comparison of three methods for measuring the attenuation provided by insert-type hearing protective devices. Prepublication article.

Hachey, G. A. and Robert, J. T. (1983). Real world effectiveness of hearing protection. American Industrial Hygiene Conference, Abstract No. 462 . 
Martin, A. (1982). How realistic are standard subjective test methods for evaluating hearing protector attenuation? In P. W. Alberti (ed.), Personal hearing protection in industry, pp. 273-298. New York: Raven Press.

Maurer, J. F. (1972). Lecture. Quarterly industrial noise workshop, Portland State University.

Michael, P. L., Kerlin, R. L., Bienvenue, G. R., Prout, J. H., and Shampan, J. I. (1976). A real-ear field method for the measurement of the noise attenuation of inserttype hearing protectors. Cincinnati: U.S. Dept. of HEW, Report No. 79-115.

Newby, Hayes A. (1979). Audiology. 4th ed. Englewood Cliffs, NJ: Prentice-Hall, Inc.

Nixon, C. W. (1982). Hearing protection standards. In P. W. Alberti (ed.), Handbook of clinical audiology. Baltimore: Williams and Wilkins.

Occupational Safety and Health Administration (1983). Occupational noise exposure; hearing conservation amendment; final rules. Federal Register, $48: 46$ (March 8), 9776. Washington, D.C.: Superintendent of Documents.

Padilla, M. (1976). Earplug performance in industrial field conditions. Sound and Vibration, 10(5), 33-36.

Regan, D. E. (1975). Real-ear attenuation of personal ear protective devices worn in industry. Doctoral dissertation, Kent State University.

(1977). Real-ear attenuation of personal ear protective devices worn in industry. Audiology and Hearing Education, $3(1), 16-17$.

Riko, K. and Alberti, P. W. (1983). Hearing protectors: A review of recentobservations. Journal of Occupational Medicine, 25 $(70), 523-526$.

Royster, L. H. and Holder, S. R. (1982). Personal hearing protection: Problems associated with the hearing protection phase of the hearing conservation program. In P. W. Alberti (ed.), Personal hearing protection in industry, pp. 447-469. New York: Raven Press. 
Royster, L. H., Royster, J. D., and Cecich, T. E. (1984). An evaluation of the effectiveness of three hearing protection devices at an industrial facility with a TWA of $107 \mathrm{~dB}$. Journal of the Acoustical Society of America, $\underline{76}(2), 485-497$.

Rudmose, wayne (1982). The case of the missing $6 \mathrm{~dB}$. Journal of the Acoustical Society of America, 71 (3), $650-658$.

Traynor, R. M., Ackley, S., and Wiernsbowsky, L. (1989). Probe tube microphone measurement of hearing protection devices. Hearing Instruments, $40(2), 32-33$.

Tobias, J. V. (1982). Measurers' choices in standard and nonstandard testing of hearing-protector effectiveness. In P. W. Alberti (ed.), Personal hearing protection in industry, po. 163-173. New York: Raven Press.

U.S. Department of Health and Human Services/PHS (1982). Hearing protectors: Field measurements. MMWR, $\underline{31}$.

Waugh, R. (1974). Pure-tone, third-octave, and octave-band attenuation of ear protectors. Journal of the Acoustical Society of America, 56(6), $1 \overline{866-1869 .}$

Webster, J. C., Thompson, P. O., and Beitscher, H. R. (1956). Noise bands versus pure-tone stimuli in measuring the acoustic attenuation of ear protective devices. Journal of the Acoustical Society of America, 28 (4), 631-638. 


\section{APPENDIX A}

INSTRUCTIONS FOR EARPLUG INSERTION FOR THE CUSTOM-MOLDED, MAX, AND V-51R EARPLUGS 
INSTRUCTIONS FOR THE EARPLUG INSERTION FOR THE CUSTOM-MOLDED, MAX, AND V-51R EARPLUGS

\section{CUSTOM-MOLDED:}

Place your thumb on the flat surface of the earplug and guide it into your ear canal. While applying pressure to the earplug with your thumb, twist it back and forth until you feel it is properly seated in your ear. Lock the upper portion of the earplug under that section of the ear.

MAX:

1. Roll MAX down with fingertips to a small diameter.

2. Keeping MAX rolleo, insert with fingertips. It may be necessary to open ear canal by reaching overhead ano pulling up and out on ear.

3. Press MAX well into ear ano hold until plug expanos.

$\underline{V-51 R}:$

Hold plug by safety tab. Insert with tab at back of ear until comfortable seal is made. 
APPENDIX B

RAW DATA 


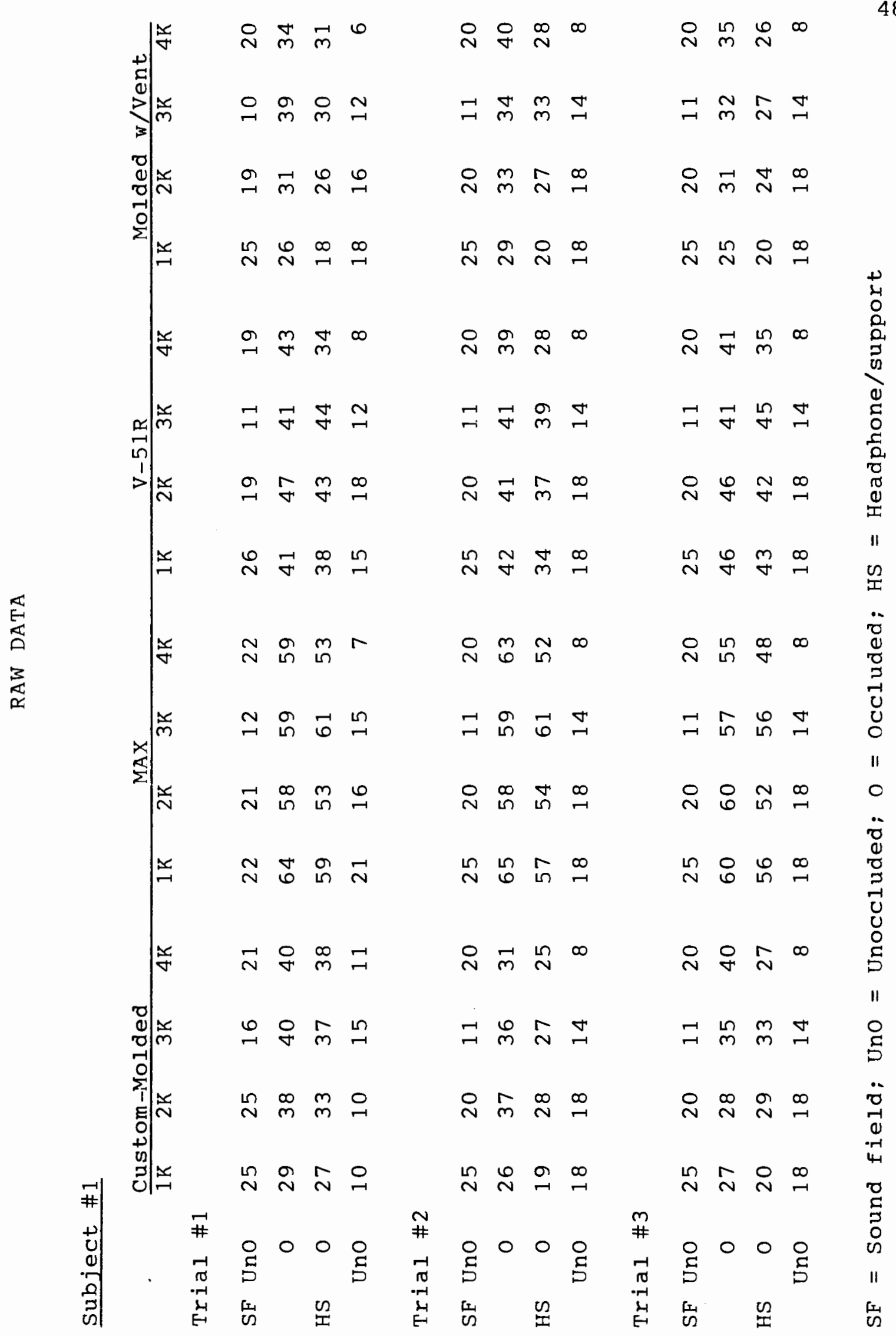




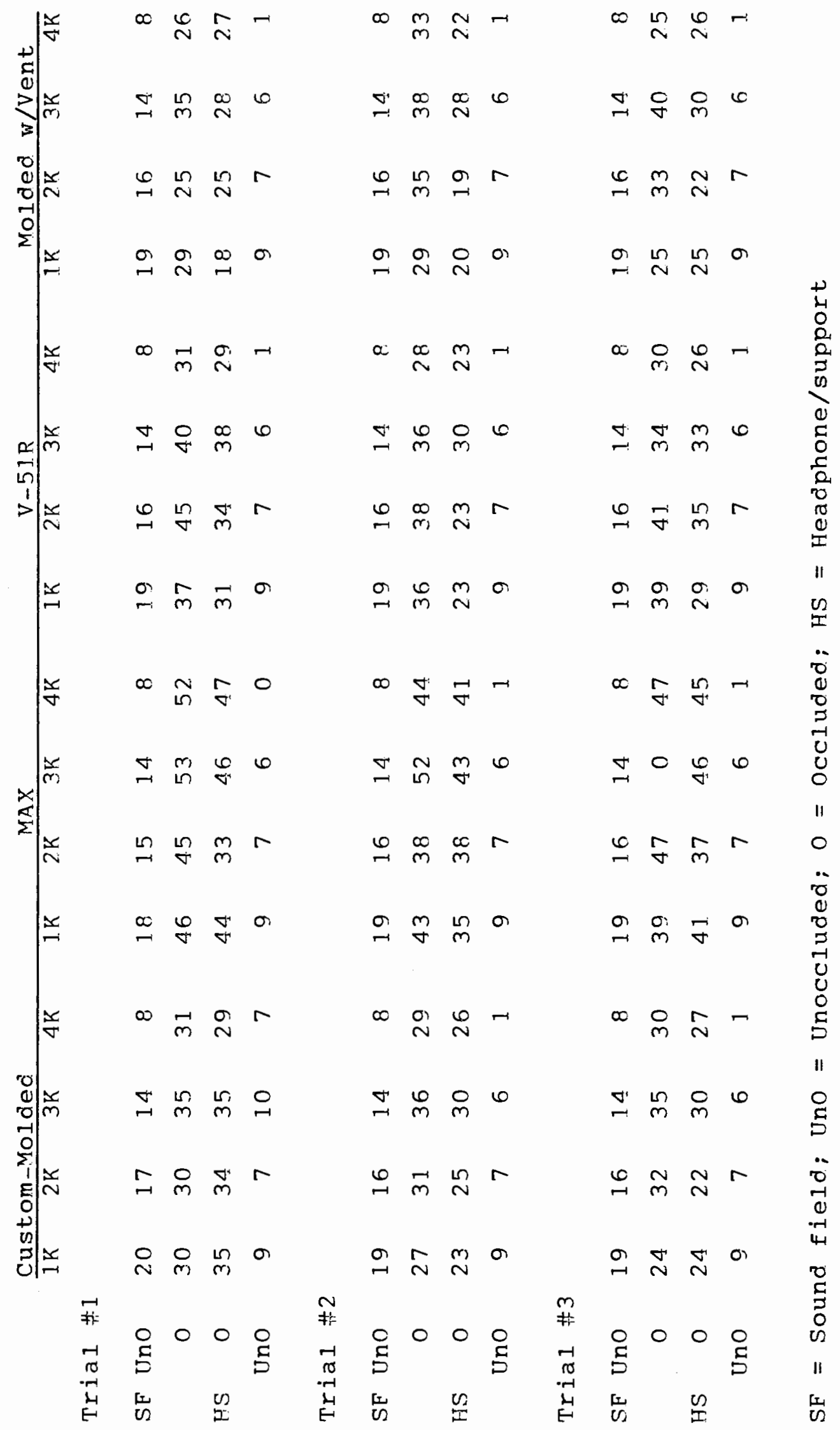




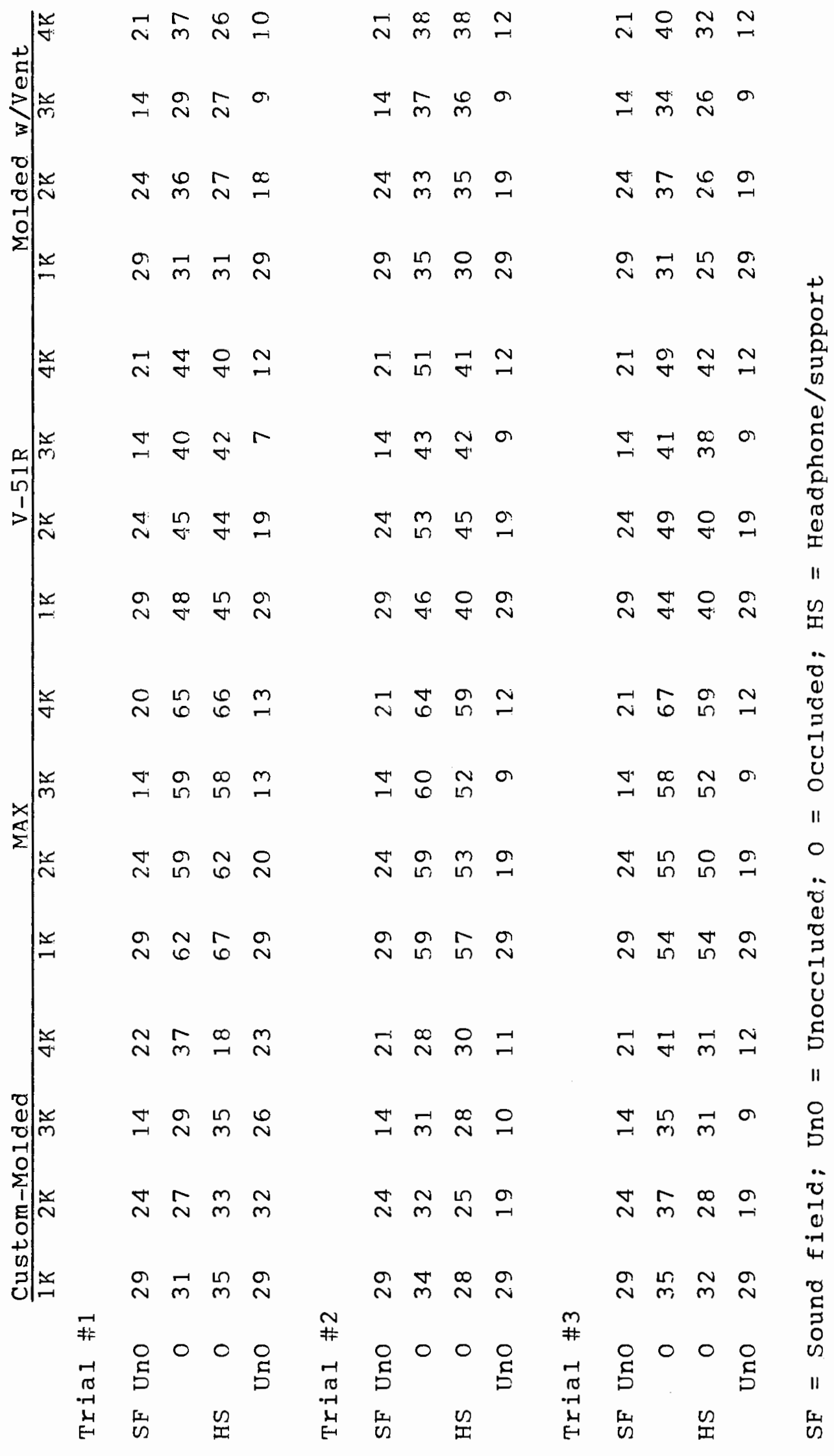




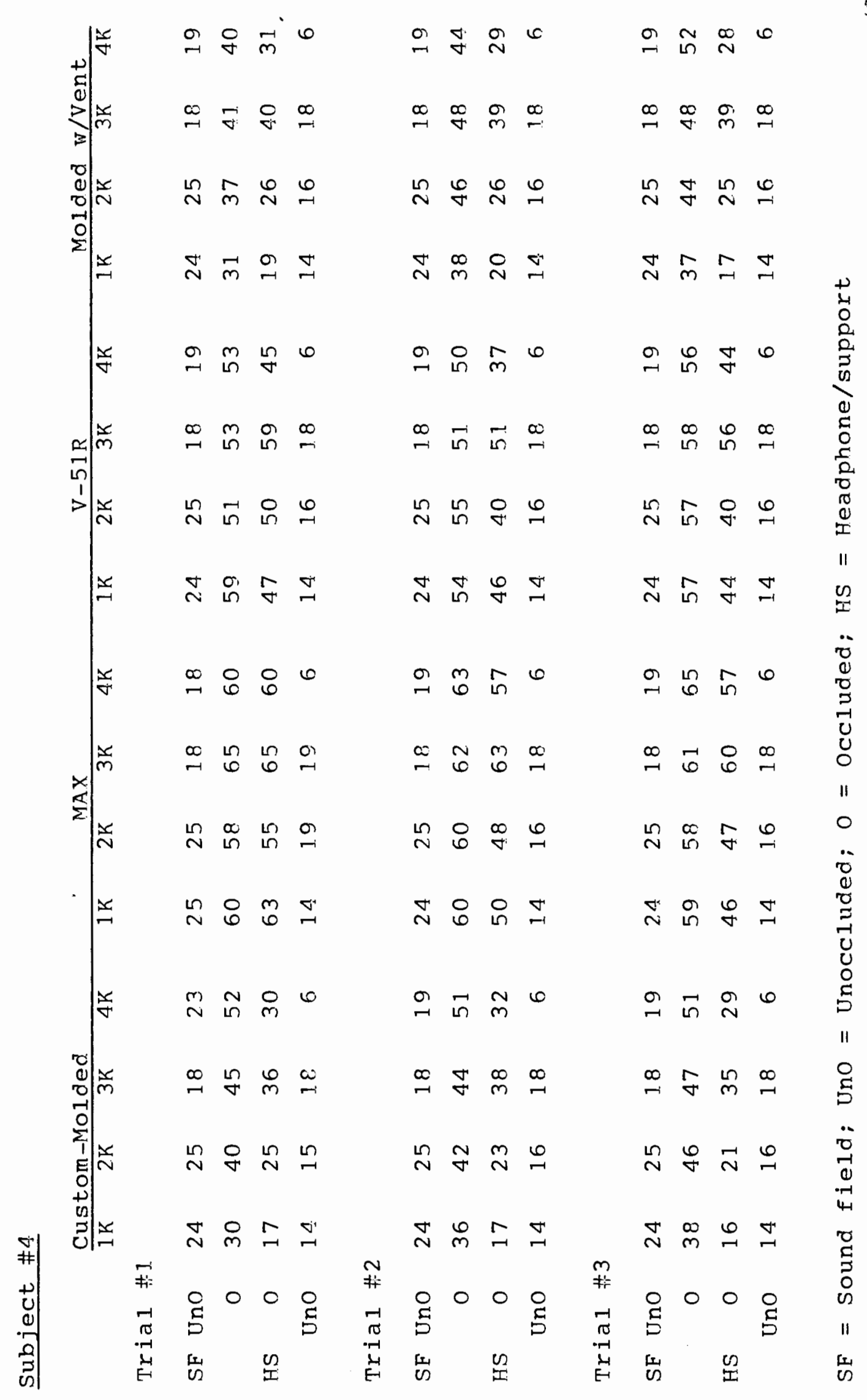




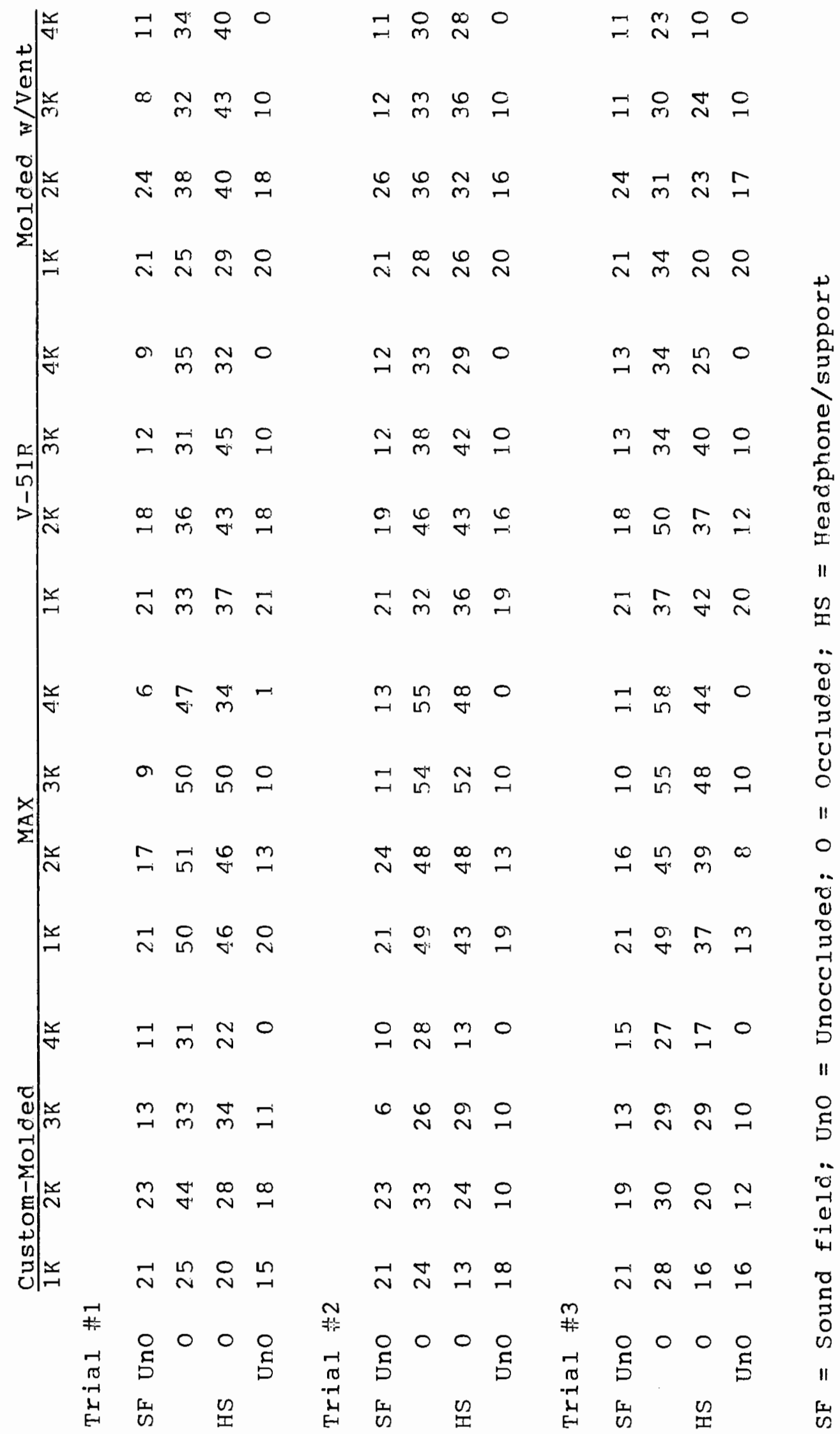




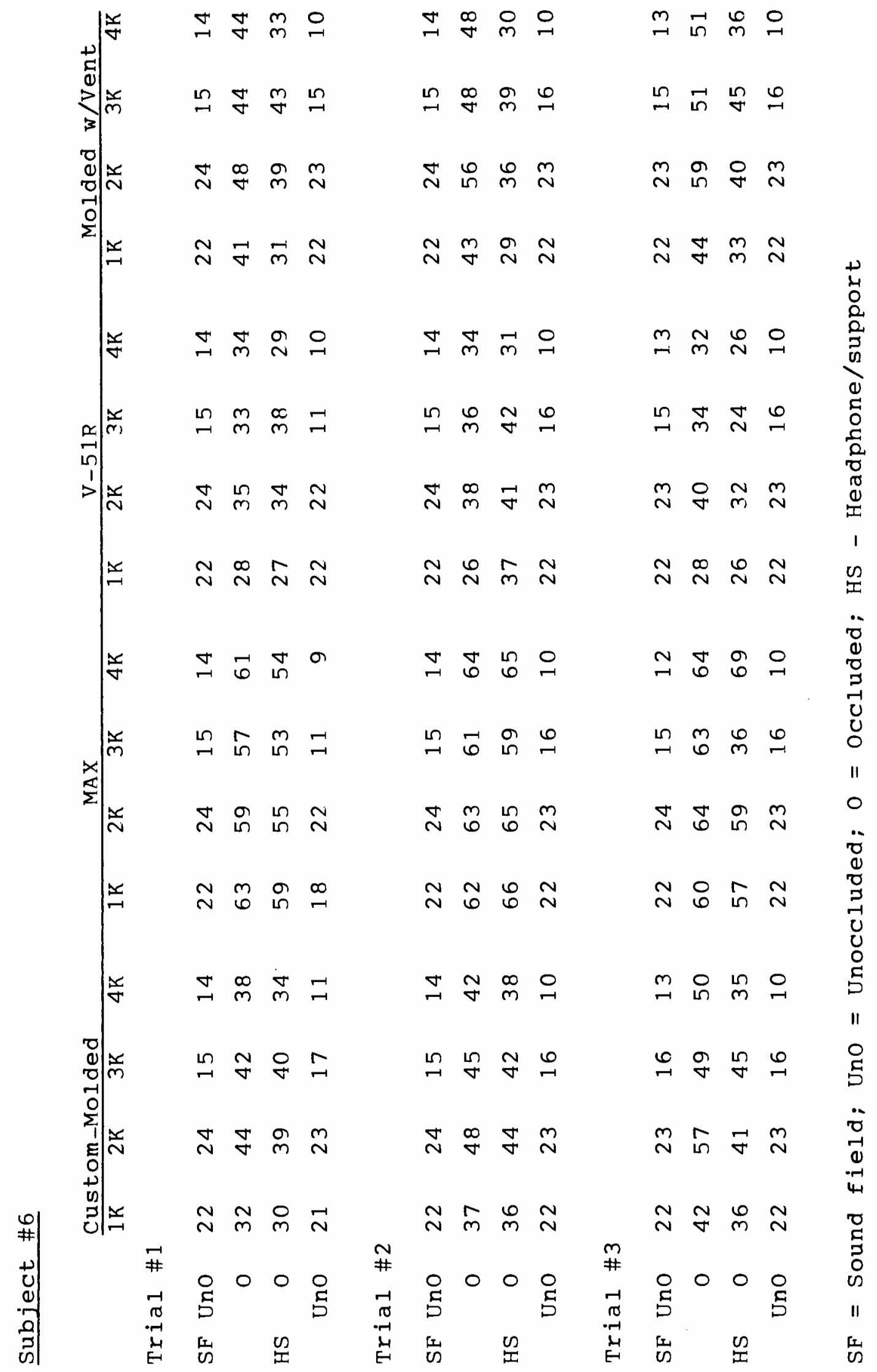




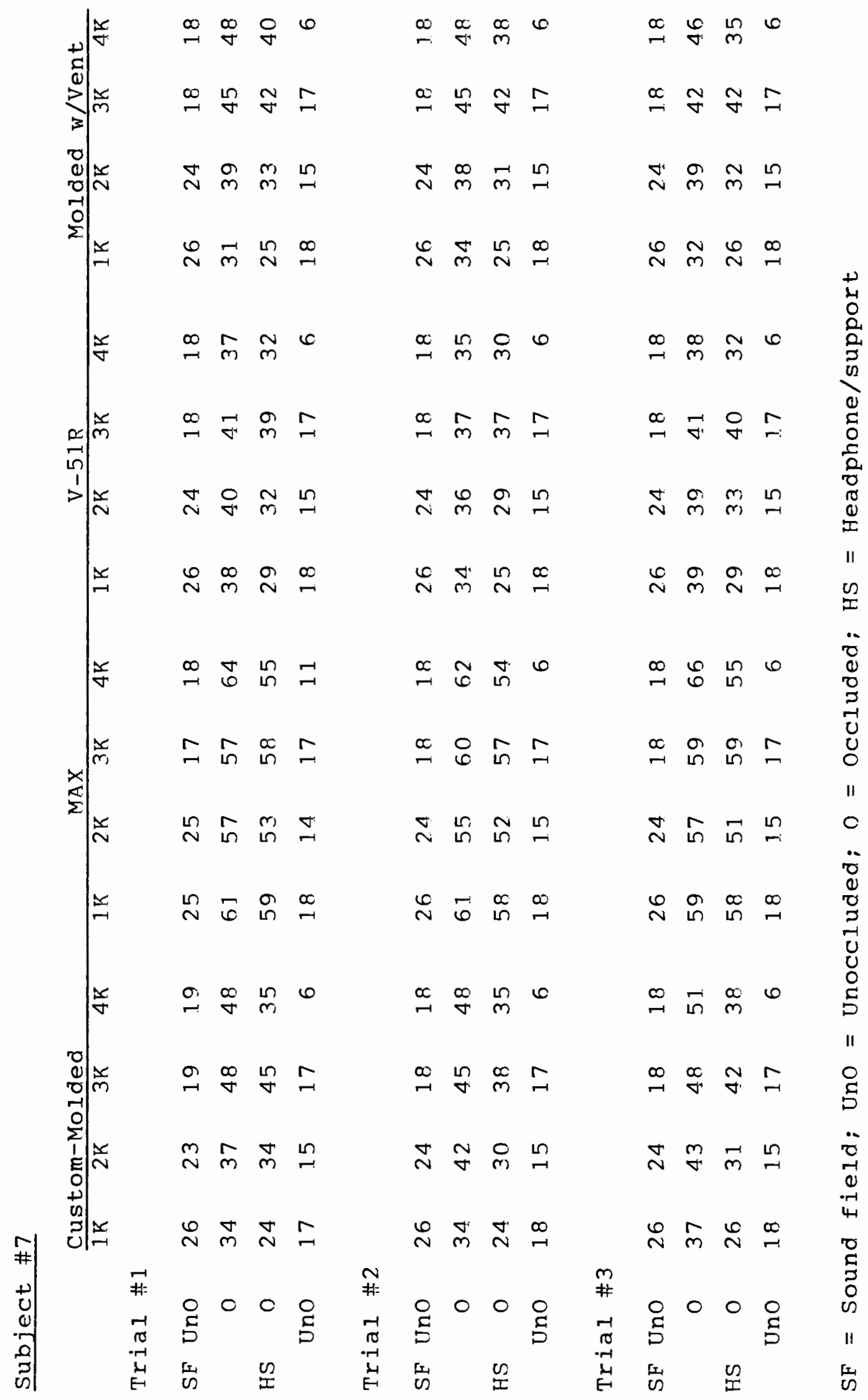




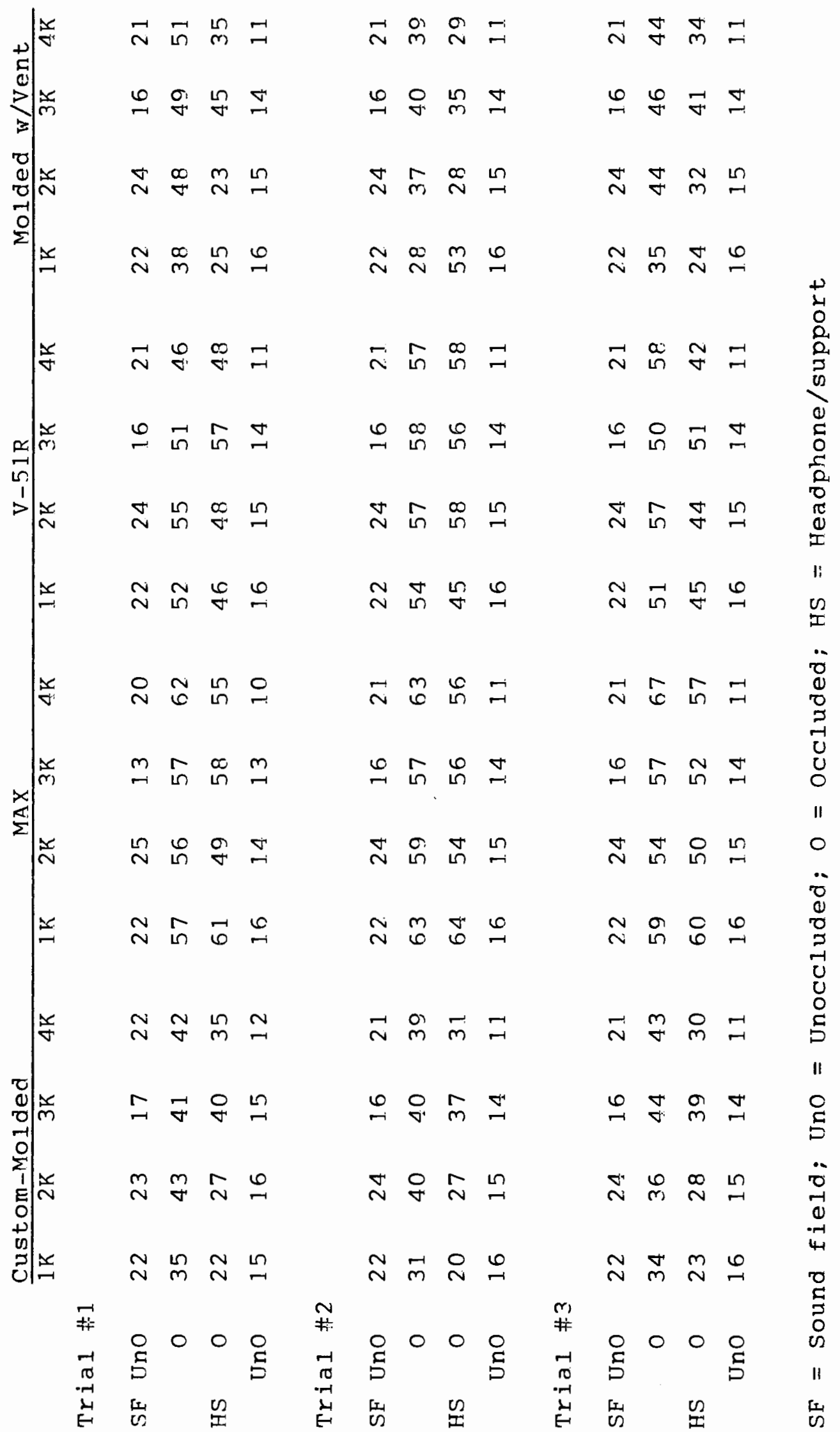




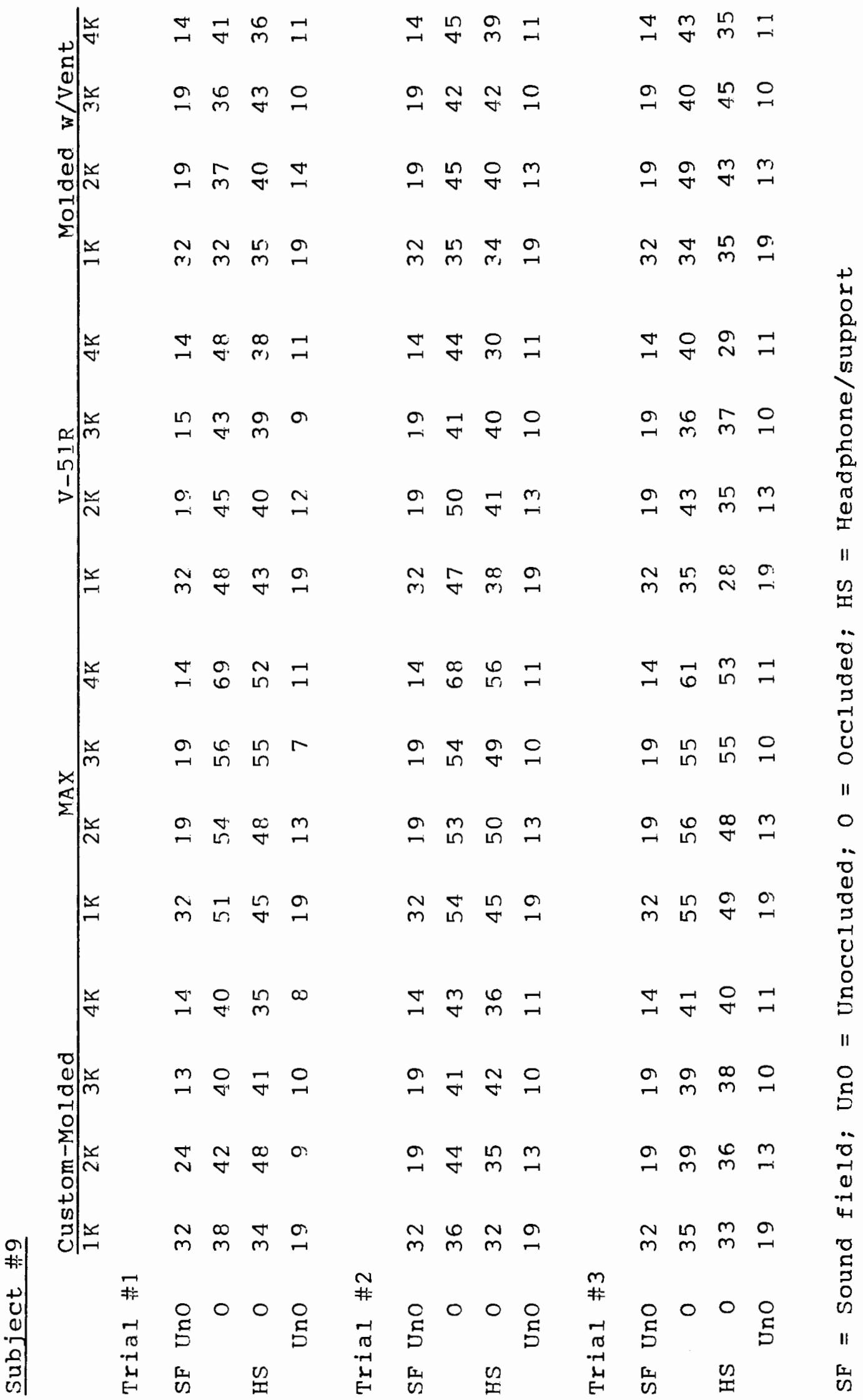




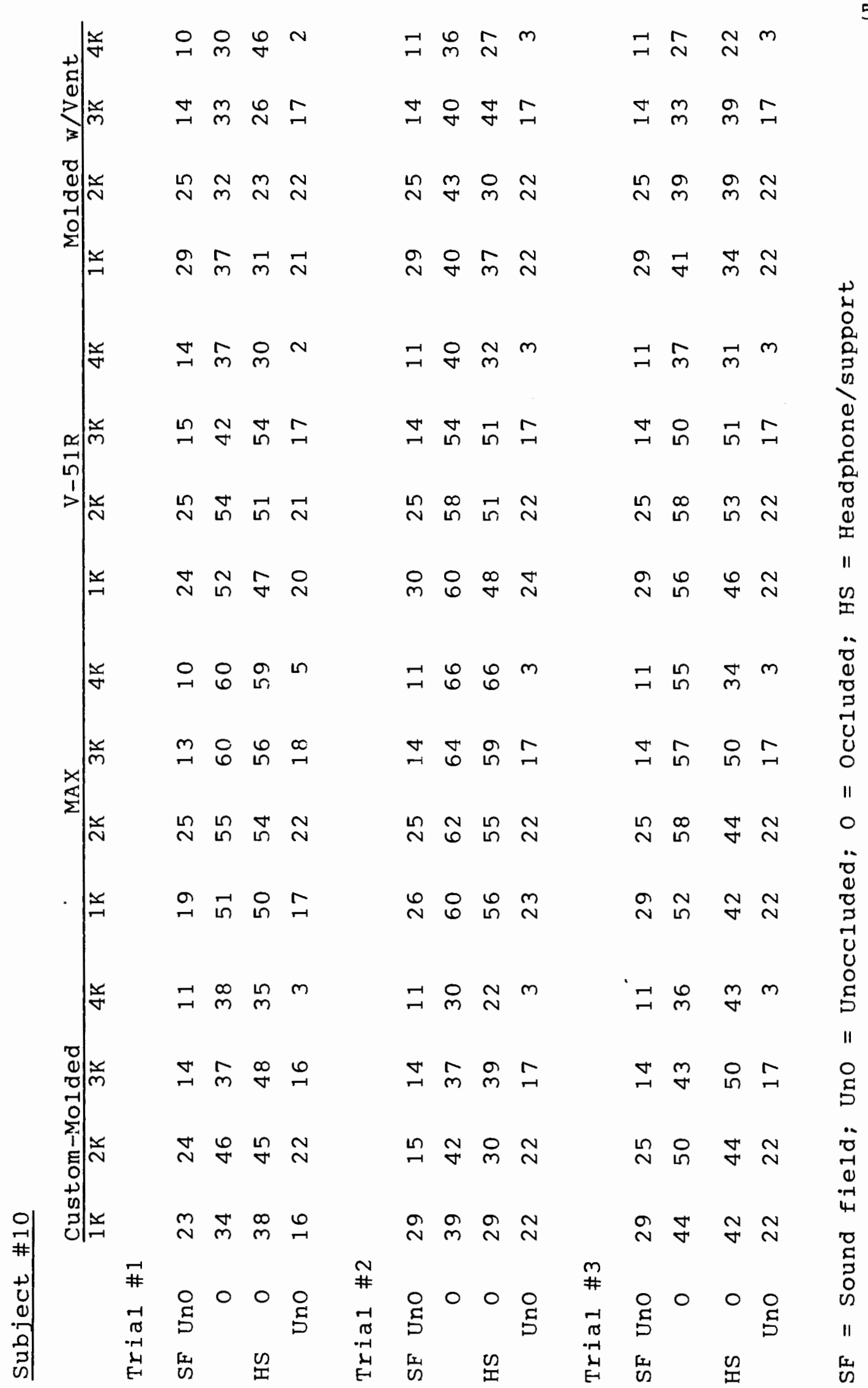




\section{APPENDIX C}

AVERAGE ATTENUATION PER PLUG-CUSTOM-MOLDED, MAX, V-51R, AND MOIJDED WITH VENT 


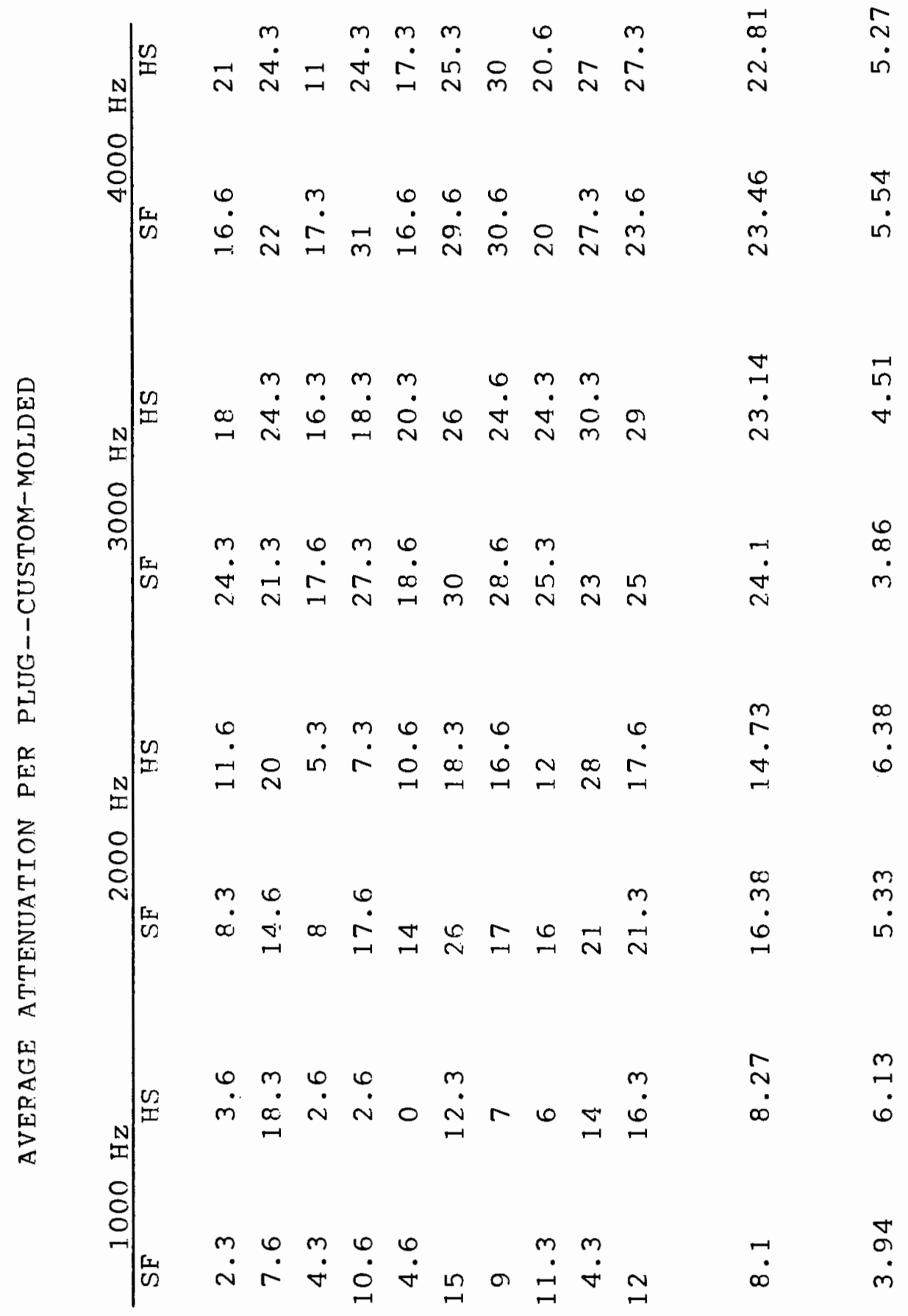

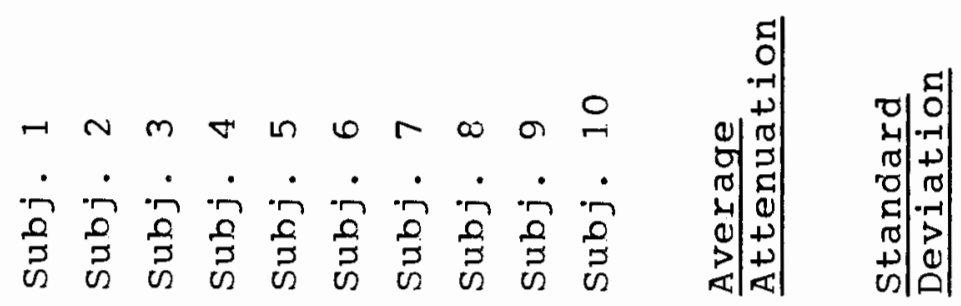




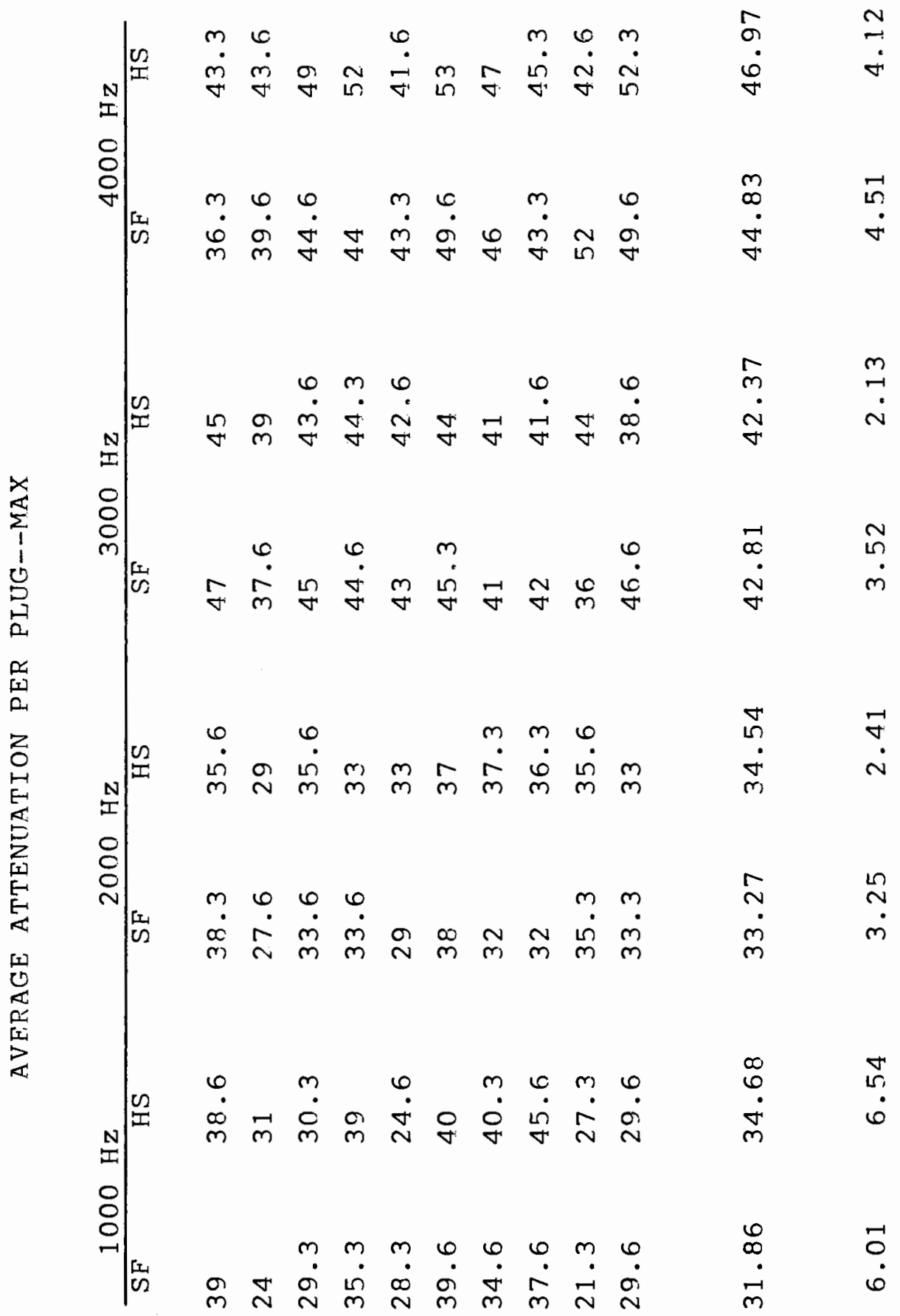

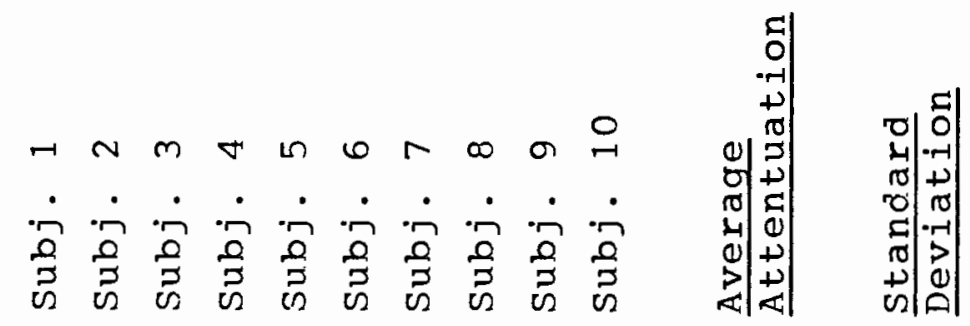




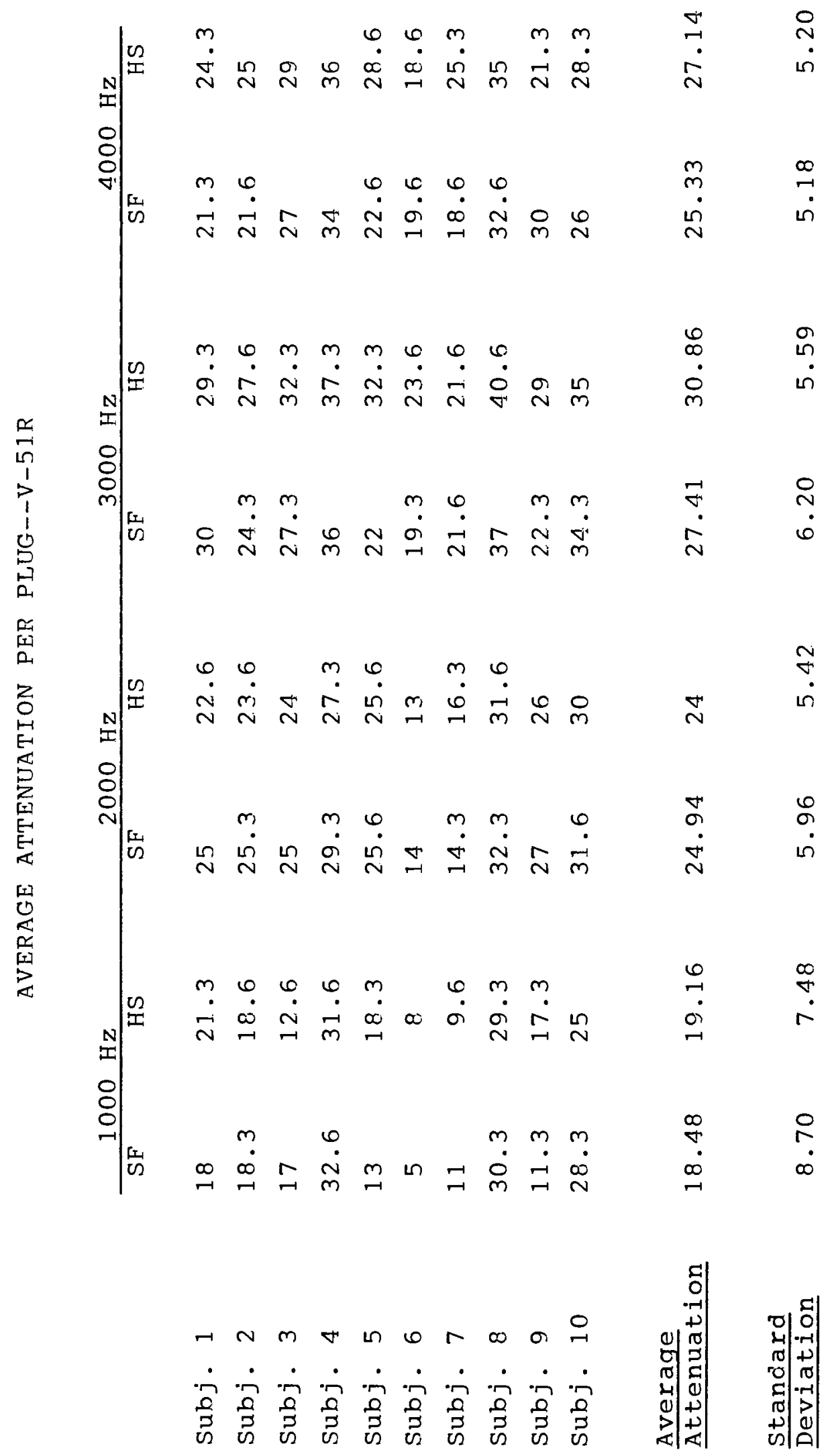




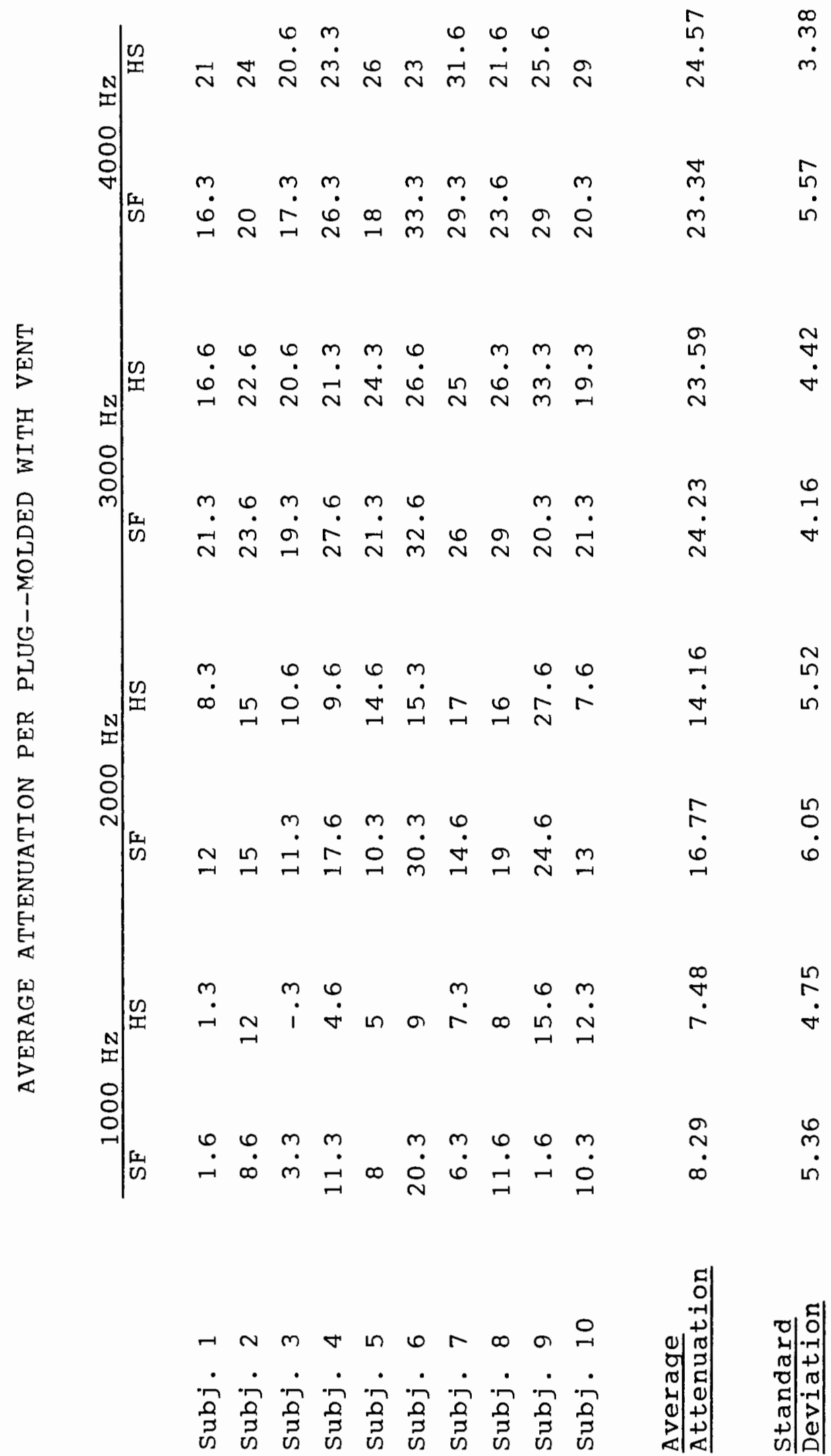


APPENDIX D

PEARSON CORRELATION COEFFICIENTS 
PEARSON CORRELATION COEFFICIENTS

$\underline{\mathrm{T} 1 \mathrm{vs} . \mathrm{T} 2} \mathrm{~T} 1 \mathrm{vs} . \mathrm{T} 3 \quad \mathrm{~T} 2 \mathrm{vs} . \mathrm{T} 3$

\begin{tabular}{|c|c|c|c|c|}
\hline $\begin{array}{ll}M 1, & F 1, \\
M 1, & F 1, \\
M 1, & F 1, \\
M 1, & F 1,\end{array}$ & $\begin{array}{l}\text { CM } \\
\text { MAX } \\
\text { V-51R } \\
\text { CMWV }\end{array}$ & $\begin{array}{l}.63 \\
.89 \\
.97 \\
.70\end{array}$ & $\begin{array}{l}.56 \\
.76 \\
.85 \\
.81\end{array}$ & $\begin{array}{l}.91 \\
.87 \\
.84 \\
.81\end{array}$ \\
\hline $\begin{array}{ll}M 1, & F 2, \\
M 1, & F 2, \\
M 1, & F 2, \\
M 1, & F 2,\end{array}$ & $\begin{array}{l}\text { CM } \\
\text { MAX } \\
V-51 R \\
C M W V\end{array}$ & $\begin{array}{l}.46 \\
.38 \\
.68 \\
.35\end{array}$ & $\begin{array}{l}.37 \\
.61 \\
.67 \\
.65\end{array}$ & $\begin{array}{l}.64 \\
.62 \\
.86 \\
.85\end{array}$ \\
\hline $\begin{array}{l}M 1, F 3, \\
M 1, F 3, \\
M 1, F 3 ， \\
M 1 ， F 3 ，\end{array}$ & $\begin{array}{l}\text { CM } \\
M A X \\
V-51 R \\
C M W V\end{array}$ & $\begin{array}{l}.84 \\
.83 \\
.65 \\
.40\end{array}$ & $\begin{array}{l}.61 \\
.60 \\
.74 \\
.69\end{array}$ & $\begin{array}{l}.81 \\
.81 \\
.82 \\
.78\end{array}$ \\
\hline $\begin{array}{l}\mathrm{M} 1, \mathrm{~F} 4, \\
\mathrm{M} 1, \mathrm{~F} 4, \\
\mathrm{M} 1 .\end{array}$ & $\begin{array}{l}\text { CM } \\
\text { MAX } \\
V-51 R \\
C M W V\end{array}$ & $\begin{array}{l}.78 \\
.63 \\
.54 \\
.53\end{array}$ & $\begin{array}{l}.69 \\
.60 \\
.56 \\
.62\end{array}$ & $\begin{array}{l}.78 \\
.40 \\
.89 \\
.71\end{array}$ \\
\hline $\begin{array}{l}M 2, \\
M 1, \\
M 2,\end{array}$ & $\begin{array}{l}\text { CM } \\
\text { MAX } \\
V-51 R \\
\text { CMwV }\end{array}$ & $\begin{array}{l}.64 \\
.74 \\
.81 \\
.86\end{array}$ & $\begin{array}{l}.81 \\
.60 \\
.81 \\
.75\end{array}$ & $\begin{array}{l}.82 \\
.70 \\
.71 \\
.85\end{array}$ \\
\hline $\begin{array}{ll}M 2, & \text { F2, } \\
M 2, & \text { F2, } \\
M 2, & \text { F2, } \\
M 2, & \text { F2, }\end{array}$ & $\begin{array}{l}\text { CM } \\
\text { MAX } \\
\mathrm{V}-51 \mathrm{R} \\
\mathrm{CMWV}\end{array}$ & $\begin{array}{l}.68 \\
.10 \\
.66 \\
.75\end{array}$ & $\begin{array}{l}.79 \\
.08 \\
.84 \\
.51\end{array}$ & $\begin{array}{l}.57 \\
.84 \\
.50 \\
.65\end{array}$ \\
\hline $\begin{array}{l}\text { M2, F3, } \\
M 2,\end{array}$ & $\begin{array}{l}\text { CM } \\
M A X \\
V-51 R \\
C M W V\end{array}$ & $\begin{array}{l}.51 \\
.33 \\
.88 \\
.16\end{array}$ & $\begin{array}{l}.62 \\
.52 \\
.75 \\
.40\end{array}$ & $\begin{array}{l}.62 \\
.08 \\
.50 \\
.40\end{array}$ \\
\hline $\begin{array}{l}\text { M2, } \\
\text { M2, } \\
\text { M2, } \\
\text { M2, } \\
\text { 2 } 4,\end{array}$ & $\begin{array}{l}\text { CM } \\
\text { MAX } \\
V-51 R \\
\text { CMWV }\end{array}$ & $\begin{array}{l}.21 \\
.36 \\
.77 \\
.36\end{array}$ & $\begin{array}{l}.51 \\
.07 \\
.81 \\
.36\end{array}$ & $\begin{array}{l}.66 \\
.19 \\
.71 \\
.01\end{array}$ \\
\hline
\end{tabular}

